NBER WORKING PAPER SERIES

\title{
PARENTAL ALTRUISM AND INTER \\ VIVOS TRANSFERS: THEORY AND \\ EVIDENCE
}

\author{
Joseph G. Altonji \\ Fumio Hayashi \\ Laurence Kotlikoff
}

Working Paper 5378

\author{
NATIONAL BUREAU OF ECONOMIC RESEARCH \\ 1050 Massachusetts Avenue \\ Cambridge, MA 02138 \\ December 1995
}

This research was supported by the National Institute of Aging (Grant \# 1RO1AG8655-01) and the Center for Urban Affairs and Policy Research, Northwestern University. Charles Pierret and Daniel Aaronson provided excellent research assistance. We are grateful to Agar Brugiavini, Bo Honore, Costas Meghir, Bruce Meyer, Christopher Udry, participants in the SPES Conference on Dynamic Models of Household Behavior in Sardinia, Italy (June 1993), as well as participants in seminars at Northwestern University, The University of Chicago, Vanderbilt, Johns Hopkins, Yale, Princeton, UCLA, and NBER for valuable comments on earlier drafts. This paper is part of NBER's research programs in Labor Studies and Public Economics. Any opinions expressed are those of the authors and not those of the National Bureau of Economic Research.

() 1995 by Joseph G. Altonji, Fumio Hayashi, and Laurence Kotlikoff. All rights reserved. Short sections of text, not to exceed two paragraphs, may be quoted without explicit permission provided that full credit, including $\odot$ notice, is given to the source. 


\title{
PARENTAL ALTRUISM AND INTER \\ VIVOS TRANSFERS: THEORY AND EVIDENCE
}

\begin{abstract}
This paper uses PSID data on the extended family to test whether inter vivos transfers from parents to children are motivated by altruism. Specifically, the paper tests whether an increase by one dollar in the income of parents actively making transfers to a child coupled with a one dollar reduction in that child's income results in the parents increasing their transfer to the child by one dollar. This restriction on parental and child transfer-income derivatives is derived for the standard altruism model augmented to include uncertain and liquidity constraints. These additional elements pin down the timing of inter vivos transfers. The paper's method of estimating income-transfer derivatives takes into account unobserved heterogeneity across families in the degree of altruism. The findings strongly reject the altruism hypothesis. Redistributing one dollar from a recipient child to donor parents leads to less than a 13 cent increase in the parents' transfer to the child - far less than the one dollar increase implied by altruism.
\end{abstract}

Joseph G. Altonji

Department of Economics

Northwestern University

Evanston, IL 60208

and NBER

Laurence Kotlikoff

Department of Economics

Boston University

Boston, MA 02215

and NBER
Fumio Hayashi

Department of Economics

Columbia University

New York, NY 10027

and NBER 


\section{Introduction}

The nature and degree of economic exchange within the family is a fundamental economic issue. As Becker (1974) and Barro (1974) formally clarified, families can play an important role in redistributing income among their members. Families can also insure their members against economic risks, many of which may not be insurable in the market place. Finally, families can play a valuable role in the provision of credit to their members. ${ }^{\prime}$

There are two principal competing explanations of family exchange. The first is that altruism leads family members to share income and provide each other with in-kind assistance of various kinds. The second is that family members are selfish and assist each other only as part of a quid-pro-quo arrangement. Distinguishing between the two views is critical for a range of issues, including the effectiveness of government inter- and intragenerational redistribution programs and the intergenerational transmission of inequality. This paper develops and implements new econometric tests of altruism based on data on intervivos transfers from parents to children.

In a previous study (Altonji, Hayashi, and Kotlikoff, 1992b), we used consumption data to test the joint hypotheses that (a) family economic links are motivated by altruism and (b) all families have operative altruistic linkages. Specifically, we examined the prediction that altruistically linked family members would share their incomes in deciding how much to consume. We found strong evidence that such income-sharing, if it occurs, is not ubiquitous. The present study complements our previous work by testing for altruism among just those parents who are actually transferring money to their children. Specifically, we test the following implication of altruism: reducing the income of the donor parents by one dollar and increasing the income of a recipient child by one dollar reduces the amount transferred by one dollar. We refer to this as the test of transfer-income derivatives. To preform this test, we

\footnotetext{
${ }^{1}$ Ben Porath (1980), Kotlikoff and Spivak (1981), Pollack (1985), Becker (1989), and numerous other studies have discussed the advantages and disadvantage of the family in performing these functions.
} 
estimate the response of transfers to the incomes of the parents and child using what we believe to be better data and a superior econometric method than underlie previous estimates. ${ }^{23}$

Our data come from the 1968-1989 Panel Study of Income Dynamics, particularly the newly released 1988 wave which contains a supplemental survey on family transfers. The PSID collects separate panel data on parents and most of their adult children. Consequently, we can control for the principal theoretical determinants of money transfers, namely the current and permanent incomes of the parents, the child, and the child's siblings.

Reliable estimation of transfer-income derivatives requires dealing with unobserved heterogeneity and sample selection bias and doing so without imposing strong functional form assumptions. As we illustrate, transfers are not likely to be an additively separable function of observed factors such as income and unobserved determinants. Consequently, standard estimation methods, such as the Tobit model or Heckman's two-step estimator, cannot be used. What can be used is a new estimation method developed in Altonji (1993). This method is robust to the functional form relating parental utility to consumption and to observed and unobserved preference characteristics. It is also robust to the distribution of unobserved heterogeneity and to certain types of measurement error in reported transfers. In particular, the responses of transfers to income may depend on unobservables and vary across families.

A theoretical concern about using transfer data to test altruism involves the timing of transfers. In certain unrealistic settings, featuring no uncertainty, no liquidity constraints, and no tax incentives for delaying or advancing transfers, the timing of a parents' transfers is indeterminate. The reason is that the child's welfare depends simply on the present value of the transfer she receives, not when she receives it.

\footnotetext{
${ }^{2}$ Our estimated transfer-income derivatives have the added advantage that they are valid regardless of whether transfers are determined by altruism.

${ }^{3}$ Altruism has other implications. For example, it implies that, conditional on an actual transfer, the composition as well as the level of expenditures by the parent and child households is not affected by marginal changes in the income of the parents and the child. We lack the data to pursue this. Thomas (1990), Browning (1994), and other recent papers examine whether the distribution of income or assets within the household affects the distribution of expenditures. Hayashi (1995) examines whether consumption patterns for parents and adult children who live together are affected by $Y_{p} / Y_{k}$.
} 
However, in realistic settings, the timing of transfers is determinate. As we show below, simply adding the assumption that parents are not absolutely certain about their own or their children's future income suffices to fix the timing of their transfers. This uncertainty leads parents to delay making transfers to their children as long as possible in order to ensure that their children don't "strike it rich," thereby obviating the need for transfers. The delay in making transfer arises no matter how small the chances are of the children striking it rich. Hence, even the prospect of their children winning the lottery will lead parents, who would otherwise be indifferent, to delay making their transfers.

This general preference for delay is balanced by other factors. Altig and Davis (1992) assume there is no uncertainty, but introduce capital market imperfections in the form of a positive gap between after-tax borrowing and lending rates. According to their model, if their children are net borrowers, parents will make all of their transfers to them when they are young. ${ }^{4}$ Like Altig and Davis, our model considers capital market imperfections, but it also includes income uncertainty. In concert, these two elements produce a time-path of transfers that balances the desire to delay transfers in order to resolve uncertainty against the desire to relieve recipients' liquidity constraints. ${ }^{5}$ Parents may make transfers early, late, or both. ${ }^{6}$ The key point is that transfers made earlier in life (the intervivos transfers we observe) are the result of some special considerations, rather than simply the reflection of a randomly chosen date at which the donor makes some or all of her transfers. With liquidity-constrained recipient children, the theoretical restriction on the transfer-income derivatives still applies. ${ }^{7}$ However, the relevant income derivatives of the child and parents are those taken with respect to current income, controlling for assets and expected future income.

\footnotetext{
${ }^{4}$ Drazen (1978) reaches the same conclusion in a model in which parents invest in their children's human capital when young.

${ }^{5}$ In their conclusion (page 1219), Altig and Davis speculate that uncertainty about incomes and longevity will give parents an incentive to delay transfers. They also call for research on a model with both capital market imperfections and uncertainty

${ }^{6}$ Although tax considerations can also pin down the timing of transfers, we leave them out of our analysis. Gift and estate taxes are a minor issue for most families since parents can shelter from taxes up to $\$ 1.2$ million in bequests and up to $\$ 20,000$ per child per year in gifts. Differences in parents' and children's marginal capital income tax rates are also likely to be small given the tax schedule of the late 1980s.

${ }^{7}$ We note in the conclusion that our test may be valid even if the timing of transfers is random.
} 
Our estimated transfer-income derivatives fail decisively to satisfy the restriction of altruism. In our data, a reduction in parents' income by $\$ 1$ reduces their transfer by less than 5 cents and a $\$ 1$ increase in the child's income reduces the transfer she receives by less than 8 cents. Consequently, shifting $\$ 1$ in current income from the parents to the child leads to less than a 13 cent reduction in the transfer. This, obviously, is far below the $\$ 1.00$ reduction predicted by the altruism model.

The paper continues in Section II by presenting a two-period model in which altruistic parents consider making transfers to a child in the context of uncertainty about the child's future income and imperfect capital markets. We show that the first-period transfer satisfies the transfer-income derivative restriction. Section $1 \mathrm{II}$ uses a simple example to illustrate a) why special care is needed in measuring transfer-income derivatives and b) the potential biases underlying Cox's (1987) estimates of these derivatives. Section IV shows how our econometric methodology overcomes these problems. Section 5 describes the data. Section 6 presents our findings, and Section 7 concludes.

\section{A Two-Period Model of Altruistic Intervivos Transfers}

In our model parents care only about their own consumption and their child's utility, i.e., they care neither about the amount per se transferred to the child (as in Blinder (1976) and Andreoni (1989)) nor about services provided them by their child (as in Bernheim, Shleifer, and Summers, 1985 and Cox, 1987). ${ }^{8}$ Our model has two periods, during which both the parents and child are alive. It also features uncertainty about the child's second-period income as well as imperfect capital markets.

By assumption, there is at least one state of the world in which the child's second period income is sufficiently high relative to that of the parents that the parents choose not to transfer to the child. In this case, if their child is not liquidity constrained, the parents will make all their transfers in the second period after they have observed the child's second period income. If their child is liquidity constrained, the parents will make some or all of their transfers in the first period. Thus, whatever transfer is observed in the first period (including a transfer of zero) represents precisely the amount the parents

\footnotetext{
8 Bergstrom (1993) provides a recent survey of theories of the family.
} 
wish to give in that period, rather than the first installment on a certain present value of lifetime transfers that could just as well be paid with interest in the second period. As we show, when the first-period transfer is positive, the difference in the partial derivatives of the transfer with respect to the parents' first-period income and the child's first-period income equals 1.

\section{The Model}

The parents have a time-separable utility function defined over their own and their child's consumption in periods 1 and 2 , i.e.,

$$
V_{1}^{p}=u\left(c_{1}^{p}\right)+\eta u\left(c_{1}^{k}\right)+E_{1}\left[u\left(c_{2}^{p}\right)+\eta u\left(c_{2}^{k}\right)\right],
$$

where $u()$ is the concave, point-in-time utility of consumption function, $E_{1}$ is the period-1 expectation operator, $\eta$ is the weight the parents places on the child's utility, $c_{1}^{p}$ stands for consumption of the parents at time 1, and the other consumption variables are defined analogously. The point-in-time utility functions of the parents and child may differ. They may also depend on additional person- and timespecific preference shifters. But we ignore these possibilities, as well as the time-preference factor, to simplify the notation.

The dynamic programming needed to maximize the parents' utility starts in the second period. When the parents and child enter that period, the child receives her previously uncertain second-period income $Y_{2}^{k}$. To keep things simple, we assume that the parents have no second-period nonasset income. After learning the value of $Y_{2}^{k}$, the parents choose a non-negative value of their second-period transfer, $R_{2}$, to maximize their second-period utility. This maximization problem is

$$
u\left(A_{2}^{p}-R_{2}\right)+\eta u\left(A_{2}^{k}+Y_{2}^{k}+R_{2}\right)
$$

s.t. $\quad R_{2} \geq 0, A_{2}^{p}-R_{2} \geq 0, A_{2}^{k}+Y_{2}^{k}+R_{2} \geq 0$, 
where $A P_{2}$ and $A_{2}^{k}$ stand, respectively, for the parents' and child's second-period assets. Equation (2.2) incorporates the assumption that the child takes the transfer of the parents as given so that her secondperiod consumption is just $A_{2}^{k}+Y_{2}^{k}+R_{2} \cdot{ }^{9}$

The solution to (2.2) satisfies

$$
u^{\prime}\left(c_{2}^{p}\right) \geq \eta u^{\prime}\left(c_{2}^{k}\right)
$$

where

$$
c_{2}^{p}=A_{2}^{p}-R_{2} \text { and } c_{2}^{k}=A_{2}^{k}+Y_{2}^{k}+R_{2}
$$

Whether or not (2.3) holds as an equality or an inequality depends on the levels of $A_{2}$ and $A_{2}^{k}$ brought into period 2 as well as the realized value of $Y_{2}^{k}$. Given $A P_{2}$ and $A_{2}^{k}$, equation (2.3) holds as an equality provided the value of $Y_{2}^{k}$ is less than or equal to a critical value, $Y_{2}^{k}$, satisfying

$$
u^{\prime}\left(A_{2}^{p}\right)=\eta u^{\prime}\left(A_{2}^{k}+\bar{Y}_{2}^{k}\right)
$$

Equation (2.4) implicitly defines $\bar{Y}_{2}$ as a function of $A^{p}{ }_{2}$ and $A^{k}$. Denoting this function by $z($, ), we can write

$$
\bar{Y}_{2}=z\left(A_{2}^{p}, A_{2}^{k}\right)
$$

Given the function $\mathrm{z}($,$) , the parents' second-period utility can be expressed as one of two$ indirect utility functions, depending on whether $Y_{2}^{k}$ is less than or equal to $z($,$) or greater than z($,$) .$ To be precise, the parents' second-period utility is

$$
\begin{aligned}
& M\left(A_{2}^{p}+A_{2}^{k}+Y_{2}^{k}\right) \text { for } Y_{2}^{k} \leq z\left(A_{2}^{p}, A_{2}^{k}\right) \text { and } \\
& N\left(A_{2}^{p}, A_{2}^{k}+Y_{2}^{k}\right) \text { for } Y_{2}^{k}>z\left(A_{2}^{p}, A_{2}^{k}\right)
\end{aligned}
$$

9 An alternative assumption, made in Kotlikoff and Rosenthal (1990), is that the child can refuse the receipt of a transfer as part of a strategy to induce the parents to increase their transfer. 
As (2.6) indicates, if the non-negativity constraint on $R_{2}$ doesn't bind and (2.3) holds as an equality, the parents' second-period utility can be written as a function $\mathrm{M}(\mathrm{)}$ ) which depends on the sum of the parents' and child's second-period resources. The reason is that (2.3) plus the constraint $c_{2}^{p}+c_{2}^{k}=$ $A A_{2}+A_{2}^{k}+Y_{2}^{k}$ can be solved together to express $c_{2}^{p}$ and $c_{2}^{k}$ as functions of $A P_{2}+A_{2}^{k}+Y_{2}^{k}$. In this case, in which $R_{2}$ is positive, we can write the solution value for $R_{2}$ as $R_{2}\left(A_{2}, A_{2}^{k}+Y_{2}^{k}\right)$.

If the non-negativity constraint on $R_{2}$ does bind, $R_{2}=0$ and the division of second-period resources between the parents and child will affect the parents' utility. In this case, we write the parents' indirect utility as a function $N\left(\right.$, ) of the parents' resources, $A\left[\right.$, and the child's, $A_{2}^{k}+Y_{2}^{k}$. Also note that when $Y_{2}^{k}=\bar{Y}_{2}^{k}$, the value of the $M($ ) and $N($, ) functions are equal.

Now consider the first period in which the child faces the intertemporal budget constraint

$$
A_{2}^{k}=\rho\left(A_{1}^{k}+Y_{1}^{k}-c_{1}^{k}+R_{1}\right)
$$

where the return on net assets function $\rho\left(\right.$ ) has the properties (i) $\rho^{\prime \prime} \leq 0$, (ii) $\rho^{\prime}(x)>0$, (iii) $\rho^{\prime}(x)>1$ when $x<x^{*}$ and (iv) $\rho^{\prime}(x)=1$ and $\rho(x)=\bar{\rho} x$ when $x \geq x^{*}$, where $\bar{\rho}$ is one plus the rate of return on net worth of relatively wealthy household. The properties of $\rho($ ) capture the idea of soft credit-market constraints; i.e., borrowing rates are higher than lending rates and the cost of borrowing rises as one's net worth falls. The parents' assets are determined by

$$
A_{2}^{p}=\rho\left(A_{1}^{p}+Y_{1}^{p}-c_{1}^{p}-R_{1}\right)=\bar{\rho}\left(A_{1}^{p}+Y_{1}^{p}-c_{1}^{p}-R_{1}\right)=\left(A_{1}^{p}+Y_{1}^{p}-c_{1}^{p}-R_{1}\right)
$$

where the second equality arises because we assume that, over the relevant range, the parents are sufficiently wealthy that they can lend at the fixed rate $\bar{\rho}$ and the third equality holds because we set $\bar{\rho}$ to 1 to simplify the algebra.

In the first period, the parents choose their first-period transfer, $\mathbf{R}_{1}$, and their first-period consumption, $\mathrm{cp}$, to solve 


$$
\max _{c_{1}^{p}, R_{1}} \quad u\left(c_{1}^{p}\right)+\eta u\left(c_{1}{ }^{k}\left(A_{1}{ }^{k}+Y_{1}+R_{1}, A_{2}^{p}\right)\right)+V\left(A_{2}^{p}, A_{2}{ }^{k} \mid I_{1}\right)
$$

where the function $V($,$) is defined by z\left(A_{2}^{p}, A_{1}^{k}\right)$

$$
V\left(A_{2}^{p}, A_{2}^{k} \mid I_{1}\right)=\int_{0} M\left(A_{2}^{p}+A_{2}^{k}+Y_{2}^{k}\right) f\left(Y_{2}^{k} \mid I_{1}\right) d Y_{2}^{k}
$$

$$
+\int_{z\left(A_{2}^{p}, A_{2}^{k}\right)}^{\infty} N\left(A_{2}^{p}, A_{2}^{k}+Y_{2}^{k}\right) f\left(Y_{2}^{k} \mid I_{1}\right) d Y_{2}^{k}
$$

and the function $c_{1}^{k}()$ is defined by

$$
\begin{aligned}
c_{1}^{k}\left(A_{1}^{k}+Y_{1}^{k}+R_{1}, A_{2}^{p}\right) \equiv & \underset{c_{1}^{k}}{\operatorname{argmax}} u\left(c_{1}^{k}\right)+\int_{0}^{z\left(A_{2}^{p}, A_{2}^{k}\right)} u\left(A_{2}^{k}+Y_{2}^{k}+R_{2}\left(A_{2}^{p}, A_{2}^{k}+Y_{2}^{k}\right)\right) f\left(Y_{2}^{k} \mid I_{1}\right) d Y_{2}^{k} \\
& +\int_{z\left(A_{2}^{p}, A_{2}^{k}\right)} u\left(A_{2}^{k}+Y_{2}^{k}\right) f\left(Y_{2}^{k} \mid I_{1}\right) d Y_{2}^{k}
\end{aligned}
$$

s.t. $\quad(2.7),(2.8)$

In (2.10) and (2.11), $f\left(Y_{2}^{k} \mid I_{1}\right)$ is the density function for $Y_{2}^{k}$ conditional on the information $I_{1}$ available in period 1, which includes $Y_{1}^{k}, Y P$, and other relevant variables. The function $V\left(\right.$, ), which depends on $I_{1}$, is the expected utility of the parents conditional on their entering the second period with $A 2$ in assets and their child entering the second period with $A_{2}^{k}$ in assets. The function $c_{1}^{k}()$, calculated in (2.11), indicates how much the child decides to consume in period 1 given her receipt of $R_{1}$. In making this decision, the child takes into account how her second-period asset position, $A_{2}^{k}$, will influence the likelihood of receiving a second-period transfer and the amount conditional on receipt, i.e., she takes into account the functions $z\left(A, A_{2}^{k}\right)$ and $R_{2}\left(A_{2}, A_{2}^{k}+Y_{2}^{k}\right)$.

The solution to problem (2.9) satisfies 


$$
\mathrm{u}^{\prime}\left(\mathrm{c}_{1}^{\mathrm{p}}\right)-\eta \mathrm{u}^{\prime}\left(\mathrm{c}_{1}^{\mathrm{k}}\right) \frac{\delta \mathrm{V}}{\delta \mathrm{A}_{2}^{\mathrm{p}}}=\frac{\delta V}{\delta A_{2}^{p}}
$$

and

$$
\eta u^{\prime}\left(c_{1}{ }^{k}\right) \frac{\delta c_{1}{ }^{k}}{\delta R_{1}}-\eta u^{\prime}\left(c_{1}{ }^{k}\right) \frac{\delta c_{1}^{k}}{\delta A_{2}^{p}} \leq \frac{\delta V}{\delta A_{2}^{p}}-\frac{\delta V}{\delta A_{2}{ }^{k}} \rho^{\prime}()\left(1-\frac{\delta c_{1}^{k}}{\delta R_{1}}-\frac{\delta c_{1}^{k}}{\delta A_{2}{ }^{p}}\right)
$$

where $\delta c_{1}^{k}() / \delta R_{1}$ is determined by differentiating the first-order conditions defining the solution to (2.11). If (2.12b) holds as an inequality, first-period transfers, $\mathbf{R}_{1}$, will be zero. We now show that if the child is sufficiently wealthy, such that the marginal interest rate $\rho^{\prime}\left(A_{1}^{k}+Y_{1}^{k}+R_{1}-c_{1}^{k}(),\right)=\bar{\rho}=1$ when $R_{1}$ is 0 , this is indeed the outcome. In the absence of liquidity constraints, the parents hold back making any transfers to the child until, possibly, the second period after they observe their child's second-period income. To see why (2.12b) holds as an inequality when the child is not liquidity constrained, consider the two equalities in (2.13).

$$
\frac{\delta V}{\delta A_{2}^{k}}=\eta E_{1} u^{\prime}\left(c_{2}^{k}\right)=\eta u^{\prime}\left(c_{1}^{k}\right) / \rho^{\prime}\left(A_{1}^{k}+Y_{1}^{k}+R_{1}-c_{1}^{k}\right)
$$

The first of these equalities follows from differentiating (2.10) with respect to $A_{2}^{k}{ }^{10}$ The second is the first-order condition arising in problem (2.11). Since $\rho^{\prime}($ ) is 1 when the child is not liquidity constrained, we can use $(2.13)$ to rewrite $(2.12 \mathrm{~b})$ as

$$
0 \leq \frac{\delta \mathrm{V}}{\delta \mathrm{A}_{2}^{\mathrm{p}}}-\frac{\delta \mathrm{V}}{\delta \mathrm{A}_{2}^{\mathrm{k}}}
$$

By differentiating (2.10) and using the definitions of the functions $M($ ) and $N($, ), it's easy to show that the right-hand side of (2.14) is positive. ${ }^{11}$ The reason is the following: in those states in which $R_{2}$ is positive, an extra dollar of parental or child assets will be allocated in the same manner and generate the

\footnotetext{
${ }^{10}$ In taking this derivative one applies $M\left(A P_{2}+A_{2}^{k}+Y_{2}^{k}\right)=N\left(A P_{2}+A_{2}^{k}+Y_{2}^{k}\right)$ and the relationships $8 N(,) / 8 A_{2}^{k}=\eta u^{\prime}\left(c_{2}^{k}\right)$ and $\delta \mathrm{M}() / 8 \mathrm{~A}_{2}^{\mathrm{k}}=\eta u^{\prime}\left(\mathrm{c}_{2}^{\mathrm{k}}\right)$, where the last equality reflects the fact that, in those states of nature in which $Y_{2}^{k} \leq \mathrm{Z}\left(\mathrm{AP}, \mathrm{A}_{2}^{\mathrm{k}}\right), \mathrm{a}$ dollar increase in the child's second period assets yields the same marginal utility whether it is spent on the parents or the child.

${ }^{11}$ In differentiating (2.10) with respect to $A A_{2}$ and $A_{2}^{k}$ one again needs to use $M\left(A P_{2}, A_{2}^{k}+Y_{2}^{k}\right)=N\left(A_{2}, A_{2}^{k}+Y_{2}^{k}\right)$. One also needs to recall that in those states in which $Y_{2}^{k} \leq Y_{2}^{k}, \delta M^{\prime}() / 8 A_{2}=\delta M() / \delta A_{2}^{k}$, while in those states in which $Y_{2}^{k}>Y_{2}^{k}, 8 N($, )$/ 8 \mathrm{~A}_{2}=u^{\prime}\left(c_{2}\right)>u^{\prime}\left(c_{2}^{k}\right)=8 N(,) / 8 A_{2}^{k}$.
} 
same marginal utility for the parents. However, in those states in which $\mathrm{R}_{2}$ is zero, an extra dollar of parental assets will be spent on the parents' consumption, while an extra dollar of the child's assets will be spent (by the child) on the child's consumption. In these states the parents' marginal utility of consumption is higher than that of the child. Since $\delta \mathrm{V} / \delta \mathrm{A}_{2}^{\mathrm{P}}$ and $\delta \mathrm{V} / \delta \mathrm{A}_{2}^{\mathrm{k}}$ refer to the marginal utility that will arise, on average, from an increase in parent and child assets, respectively, and since this average is taken over states in which $R_{2}$ is positive and states in which $R_{2}$ is negative, it follows that $\delta \mathrm{V} / \delta \mathrm{A} 2$ exceeds $\delta \mathrm{V} / \delta \mathrm{A}_{2}^{\mathrm{k}}$.

Since the right-hand side of (2.14) is positive, we have the first result we've set out to prove. In the absence of liquidity constraints facing the child, the non-negativity constraint on first-period transfers binds and first-period transfers are zero. Intuitively, if the child is not liquidity constrained, her own intertemporal utility maximization obviates the parents' need to worry about appropriately allocating the child's consumption over time. This leaves the parents free to hold back their transfers until the second period, when they can see how much the child really needs.

Now take the case in which the child is liquidity constrained in the absence of a first period transfer, with $\rho^{\prime}\left(A_{1}^{k}+Y_{1}^{k}+R_{1}-c_{1}^{k}()\right)>1$ when $R_{1}$ is 0 . Using (2.13), one may re-write (2.12b) as

(2.15a) $0 \leq \frac{\delta V}{\delta A_{2}^{p}}-\frac{\delta V}{\delta A_{2}^{k}} \rho^{\prime}\left(A_{1}^{k}+Y_{1}^{k}+R_{1}-c_{1}^{k}\right)$.

If this condition fails to hold when $R_{1}$ is 0 , then transfers will be positive. In this case, the marginal loss to the parents from reducing $A_{2}^{P}$ by a dollar and increasing $A_{2}^{k}$ by a dollar (i.e., from transferring a dollar), which is given by $\delta V / \delta A_{2}^{k}-\delta V / \delta A_{2}$, is smaller than the marginal gain from being able to transfer to a child facing a value of $\rho^{\prime}$ in excess of 1 , which is given by $\left(\rho^{\prime}-1\right) \delta \mathrm{V} / \delta \mathrm{A}_{2}^{\mathrm{k}} .{ }^{12}$

Another way to view the problem is to use (2.12a) and (2.13) to re-write (2.12b) or (2.15a) as

\footnotetext{
12 In the case in which the parents are also subject to liquidity constraints, one may show that transfers will be zero, if, when $R_{1}$ is 0 , the marginal interest rate faced by the parents is greater than or equal to the marginal interest rate faced by the child. Transfers may be positive if the child faces an interest rate that is sufficiently higher than that facing the parents when $R_{1}$ is 0 .
} 


$$
u^{\prime}\left(c_{1}{ }^{p}\right) \geq \eta u^{\prime}\left(c_{1}^{k}\left(A_{1}^{k}+Y_{1}^{k}+R_{1}, A_{1}^{p}\right)\right)
$$

The right-hand side is decreasing in $R_{1}$. If we use the remaining equations in the model to solve for $c p$, we can determine whether the left-hand-side of $(2.15 \mathrm{~b})$ is less than the right-hand side when $R_{1}=0$. If it is, $(2.15 b)$ won't be satisfied with $R_{1}=0$, but instead requires a positive value for $R_{1}$. In the case that $R_{1}$ is positive, (2.15a) and (2.15b) hold as equalities.

We can now turn to the model's restriction on transfer-income derivatives. It is easy to check that in the objective function and constraints that determine the model's six endogenous variables $\left(\mathrm{c}_{1}^{\mathrm{k}}\right.$, $c p, c_{2}^{k}, c_{2}, R_{1}$, and $R_{2}$ ), the variables $Y p, Y_{1}^{k}$ and $R_{1}$ appear in the linear combinations $Y_{1}^{p}-R_{1}$ or $Y_{1}^{k}+$ $R_{1}$ (See equations $2.7,2.8$, and problem 2.11). Consequently, if we increase $Y_{1}^{p}$ by $\epsilon$ and decrease $Y_{1}^{k}$ by $\epsilon$, then $R_{1}$ will increase by $\epsilon$ and all the other variables will be unchanged. Hence we have

$$
\frac{\delta R_{1}}{\delta Y_{1}^{p}}-\frac{\delta R_{1}}{\delta Y_{1}^{k}}=1
$$

which forms the basis of our test of altruism.

Note that the derivatives in (2.16) are taken holding the state variables entering the $c_{1}^{k}()$ and $V\left(\right.$, ) functions constant, including the variables in the information set $I_{1}$ used to forecast future income. As discussed below, in our econometric analysis we attempt to control for these state variables. To the extent we are unsuccessful, the predicted difference in transfer-income derivatives will likely exceed 1. The reason is that if, in the cross section, higher values, across observations, of $Y_{1}^{p}$ and $Y_{1}^{k}$ arise due to differences across observations in unobserved state variables, these unobserved state variables are likely to be associated with higher values of future income. Consequently, $\delta R_{1} / \delta Y q$ will be larger and $\delta R_{1} / \delta Y_{1}^{k}$ will be smaller than if the state variables had not changed, i.e., higher values of the parents' future income will induce the parents to make larger transfers in the present as well as the future and higher values of the child's future income will induce the parents to reduce their transfer in the present as well as the future. Thus, failure to control for unobserved state variables is likely to raise the first 
term and lower the second term on the left-hand side of (2.16), producing a value for the difference in the two terms that exceeds $1 .{ }^{13}$ The derivatives in (2.16) also depend on the preference parameter $\eta$. This dependence is discussed at length in Section 3.

\section{Extensions of the Model}

Does the restriction (2.16) hold in all models in which parental preferences depend only on their own consumption and the utility of others? In the one-period case we have shown that it holds for two-sided preferences (in which the child also cares about the parents) and that it does not depend on the form of the utility functions. As noted below, it also holds in the case of more than one child, provided that the incomes and needs of the other children are held constant. Indeed, the restriction will hold in any model in which the parents' lifetime utility, after maximizing with respect to current consumption and transfers to others, depends on $R_{1}, Y_{\rho}^{p}$, and $Y_{1}^{k}$ through the differences $Y_{1}^{p}-R_{1}$ and $Y_{1}^{k}$ $+R_{1}$.

Drazen (1978), Becker (1991), and others have investigated models in which altruistic parents choose between investing in a child's human capital and making monetary transfers when the child has left school. We have analyzed a three-period version of our model in which in period 0 parents may choose to make transfers to adolescent children to overcome liquidity constraints that would limit schooling investments or to induce children who are misinformed about the value of school to stay in school longer. Parents do not make all transfers in period 0 for the same reason that they wish to delay transfers in our two-period model. The restriction (2.16) holds for period-1 transfers even though the child's income and the parent's wealth will be affected by earlier investments. However, the fact that the child's income and the parents' wealth will depend on preferences $\eta$ raises econometric issues.

At the other end of the lifecycle, adding a period 3 to the model with uncertainty about whether the parents will survive does not change the result. Parents will make transfers in period 2 and/or

\footnotetext{
${ }^{13}$ We consider below measurement error in the current income of the parents and child.
} 
period 1 if the children are liquidity constrained and the restriction (2.16) will hold. The child will receive a bequest at the end of period 2 if the parent dies.

If the child's income depends on endogenous labor supply decisions and the parents know that the child will reduce work effort in response to attempts by the parents to "tax" earnings by reducing transfers, then the difference in derivatives in (2.16) will be less than 1 . The transfer-income derivatives restriction will also fail if the parents do not know the child's income. We return to both of these issues in Section 7. Finally, the restriction will fail to hold if one drops the assumption that the child takes the first-period transfer as given and replaces the reaction function determined by (2.11) with bargaining structures in which the child can refuse to accept a transfer (see footnote 8).

\section{Econometric and Data Issues in Estimating the Efrects of Income on Transfers}

This section uses a simple static model to highlight some important issues that arise in estimating transfer-income derivatives. As part of this discussion, we briefly review previous studies that have examined the income derivatives of transfers, paying special attention to Cox's (1987) well know paper.

Assume that parents' utility, $V^{p}$, is logarithmic in their own consumption, $C_{p}$, and the consumption of their child, $\mathrm{C}_{\mathrm{k}}$, and can be written as

$$
V^{p}=\log C_{p}+\eta \log C_{k}
$$

where $\eta$ is the unobserved relative weight the parents place on the child's log consumption and is distributed across parents according to the density $g(\eta)$. This utility function is chosen for expository purposes. As indicated below, our estimates of transfer-income derivatives are non parametric; i.e., they don't assume a specific functional form for preferences. The condition for positive transfers from the parents to the child is $\eta>Y_{k} / Y_{p}$. The amount that is transferred, conditional on transfers being positive, is

$$
R=\frac{-Y_{k}+\eta Y_{p}}{1+\eta}
$$


Note that $\delta R / \delta Y_{p}-\delta R / \delta Y_{k}$ equals 1 regardless of the value of $\eta$ of the particular family, so the example illustrates the restriction we test. Also note that the unobservable $\eta$ enters the formula for $\mathrm{R}$ in a nonlinear manner. Such nonlinearity appears to be a generic property of transfer equations based on the altruism model. This invalidates the use of the standard Tobit model as well as Heckman's (1978) generalized Tobit models to estimate the response of transfers to $Y_{p}$ and $Y_{k}$. A final, obvious point, is that, unless $Y_{k}$ and $Y_{p}$ are independent, one must control for $Y_{p}$ when estimating the partial effect of $\mathrm{Y}_{\mathrm{k}}$, and vice versus.

We know of no previous empirical studies that have focussed on (2.16) as the basis of a test of altruistic preferences. However, several studies have examined the effects of either $Y_{p}$ or $Y_{k}$ on transfers and a few have simultaneously estimated the effects of both $Y_{p}$ and $Y_{k}$ without assessing the transfer-income derivative restriction. Dunn (1993) reviews these studies. ${ }^{14}$ A few generalizations may be made. With the exception of Altonji et. al. (1992b), Dunn (1993), and Rosenzweig and Wolpin (1993 and 1994), which use matched intergenerational panel data from the National Longitudinal Surveys of Labor Market Experience, most studies are based on a single cross-section survey that reports only the income of the donor. ${ }^{15}$ Few studies distinguish among the effects of permanent income and current income of both the parent and child or control for the incomes of siblings. Second, most of the studies that examine transfer amounts use OLS, Tobit, or generalized Tobit as the estimation procedure.

Probably the best known study of the effects of income on transfers is Cox (1987), which tests a sign restriction on $\delta R\left(Y_{p}, Y_{k}, \eta\right) / Y_{k}$ rather than (2.16). In Cox's model, parents desire services from their children and pay for them by making transfers. Because of this feature, the partial derivative

\footnotetext{
14 Gale and Scholz (1994) provide a useful descriptive analysis of transfer patterns using the Survey of Consumer Finances and other sources.

15 For example, several studies by Cox and his collaborators use the President's Commission on Pension Policy data set and proxy parents' income by the mean income in the survey block in which the parents reside. Cox and Jappelli (1990) use the Survey of Consumer Finances which doesn't report parents' income. They focus on liquidity constraints and transfers and find a negative effect of the child's current income controlling for an instrument for permanent income that they construct from an earnings function. Cox and Rank (1991) use the National Survey of Families and Households. They construct an instrument for donors' income based on donors' schooling, occupation, and age. See Dunn (1993) and Shoeni (1993) for additional references.
} 
$\delta R\left(Y_{p}, Y_{k}, \eta\right) / Y_{k}$ may be positively or negatively related to the child's income, in contrast to the unambiguous prediction of the altruism model that this derivative is negative. Cox reports a positive value for this partial derivative which he interprets as evidence that transfers are motivated by familial exchange of services.

There are two potential problems with Cox's evidence that may render his findings fully consistent with altruism. First, Cox's data contain no direct measure of $Y_{p}$. Although Cox constructs several imaginative estimates of $Y_{p}$, none is fully convincing. We show below that if parents are altruistic toward their child, failure to control for parents' income in estimating the derivative of $R$ with respect to $Y_{k}$ can lead to a positive rather than a negative estimate of this derivative.

The second problem is that Cox's test fails to deal appropriately with the distribution of $\eta$. Consequently, sample selection bias may affect the sign as well as the magnitude of Cox's OLS and other estimates of $\delta \mathrm{R} / \delta \mathrm{Y}_{\mathrm{k}}$. His OLS test amounts to asking whether the expected value of transfers given a positive amount, $E\left(R / Y_{p}, Y_{k}, R>0\right)$, rises with $Y_{k}$ for a given value of $Y_{p}$. This expectation is

$$
E\left(R / Y_{p}, Y_{k}, R>0\right)=\int_{Y_{k} / Y_{p}}^{\eta^{\max }} \frac{-Y_{k}+\eta Y_{p}}{1+\eta} \frac{g(\eta) d \eta}{P_{R}\left(Y_{p}, Y_{k}\right)},
$$

where $P_{R}\left(Y_{p}, Y_{k}\right)$ is Prob $\left(\eta>Y_{k} / Y_{p}\right)$. Holding $Y_{p}$ fixed, a higher value of $Y_{k}$ reduces the amount being transferred at any given value of $\eta$ at which a transfer occurs, but it also restricts the range over which transfers occur to higher values of $\eta$. Consequently, the impact on $E\left(R \mid R>0, Y_{p}, Y_{k}\right)$ is ambiguous. Intuitively, the richer the child, the less she'll receive from her parents. But as we consider richer and richer children who are receiving transfers, holding the parents' income fixed, we are also considering parents with stronger degrees of altruism, weaker tastes for consumption goods, and/or 
children with stronger tastes for consumption. ${ }^{16}$ One may easily show that $\delta E\left(R \mid R>0, Y_{p}, Y_{k}\right) / \delta Y_{k}$ is equal to

$$
\int_{Y_{k} / Y_{p}}^{\eta_{\text {mex }}} \frac{g(\eta)}{(1+\eta) P_{R}\left(Y_{k}, Y_{p}\right)} d \eta+\frac{1}{Y_{p}} E\left(R \mid R>0, Y_{p}, Y_{k}\right) \frac{P^{\prime}\left(Y_{k} / Y_{p}\right)}{P_{R}\left(Y_{k} / Y_{p}\right)}
$$

The first term is the expected value over the distribution of $\eta$ of $\left.E\left\{\delta R / Y_{p}, Y_{k}, \eta, R>0\right) / \delta Y_{p}\right\}$. It lies between 0 and -1 regardless of $g(\eta)$. The second term is positive and captures the effects of sample selection. In general, the form of the transfer equation (3.1), the distribution of $g(\eta)$, and the range of variation in $Y_{k}$ and $Y_{p}$ will determine the relative sizes of the two terms. However, for the logarithmic utility case we have constructed examples in which the second term dominates and $\delta E\left(R / R>0, Y_{p}\right.$, $\left.\mathrm{Y}_{\mathrm{k}}\right) / \delta \mathrm{Y}_{\mathrm{k}}$ has the positive sign reported by Cox. ${ }^{17}$ Hence, we conclude that Cox's test may be biased against the altruism hypothesis.

\section{Econometric Methods}

Our method for estimating income-transfer derivatives is based on the following version of

$$
\frac{\delta R(Z, \eta)}{\delta Y_{p t}}-\frac{\delta R(Z, \eta)}{\delta Y_{k t}}=1
$$

\footnotetext{
16 The nonlinearity of the model in combination with sample selection may contribute to bias. The amount of income that will be shifted in response to a given difference in the preferences of parents and the child will depend on the level of income of the parents and kids, holding the ratio constant. In this case, the mean and variance of positive transfers could be positively related to the child's as well as the parents' income. The mean of a random variable that is truncated from below is positively related to dispersion of the untruncated distribution in many cases. As a crude check on the empirical significance of this issue, we modified the Tobit models of $R$ reported below to allow the coefficients and error variance of a Tobit model of money transfers from parents to kids to depend on whether the average of the permanent incomes of the parents and the kids was in the top third of the distribution of these averages. The Tobit coefficients and the error variance are, in fact, substantially larger for parent-kid pairs with high incomes than for other families.
}

${ }^{17}$ Cox also reports Tobit and generalized Tobit estimates. As mentioned, these estimators are inappropriate given the nonlinear manner in which preferences and income affect transfers. Selectivity may also bias these estimators. 
which holds provided that $R$ is positive. The terms $Y_{p t}$ and $Y_{k t}$ are the current nonasset income of the parents and child, respectively. The variable $Z$ denotes the vector $\left\{Y_{p t}, Y_{k t}, X\right\}$, where the vector $X$ contains current wealth, the determinants of expected future income, and observed preference shifters. The variable $\eta$ is redefined to be a vector (as opposed to a scaler function) of unobservable preference variables.

There are two problems in implementing a test based on (4.0). First, $\eta$ is unobserved, so (4.0) cannot be evaluated for any particular family. Second, one needs to estimate the transfer-income derivatives entering (4.0) taking account of sample selection restrictions on $R()$ and the fact that the restriction (4.0) holds only when $R>0$. As noted, standard approaches such as the Tobit model or the Heckman's two-step estimator cannot be used to form consistent estimates of the derivatives with respect to $Y_{p t}$ and $Y_{k t}$ of $R(Z, \eta \mid Z, R>0)$ because $R(Z, \eta)$ cannot be written as the sum of functions of $\mathrm{Y}_{\mathrm{pt}}, \mathrm{Y}_{\mathrm{kt}}$, and $\mathrm{X}$ and a function of $\eta^{18}$ Generalizing the maximum likelihood Tobit procedure to models that are nonlinear in $\mathrm{Z}$ and $\eta$ and have non-normal errors requires a specific assumption about how the unobservables interact with the observables. Using the wrong form could lead to rejection of the restriction even though it is valid.

We deal with the first problem by integrating over $\eta$ and basing our test on the expectation over $\eta$ of the $\eta$-constant income derivatives. In so doing, we take advantage of the fact that under the null hypothesis the restriction (4.0) holds for all families with $R>0$. We deal with the second problem by using Altonji's (1993) estimator for expected values of partial derivatives in nonlinear limited dependent variables models.

Let $\eta^{*}(Z)$ be the set of values of $\eta$ such that $R>0$. Let $g(\eta)$ be the density of $\eta$. We assume that the distribution of $\eta$ is independent of $Z$.

$$
P_{R}\left(Y_{p t}, Y_{k t}, X\right)=\int_{\eta^{\prime}\left(Y_{p t}, Y_{k x}, X\right)} g(\eta) d \eta
$$

\footnotetext{
${ }^{18}$ For some functional forms, such as the specification underlying (3.1) above, a transformation of the transfer equation has a Tobit-type structure, although not necessarily with normal errors. However, this particular choice of functional forms is arbitrary.
} 
is the $\operatorname{Prob}(\mathrm{R}>0 \mid \mathrm{Z})$. Then

$$
E\left(\frac{\delta R(Z, \eta)}{\delta Y_{\mu}} Z, R>0\right)=\int_{\eta^{\prime}(Z)} \frac{\delta R(Z, \eta)}{\delta Y_{j t}} \cdot \frac{g(\eta) d \eta}{P_{R}(Z)} ; j=p, k
$$

and

$$
E\left(\frac{\delta R(Z, \eta)}{\delta Y_{p}}-\frac{\delta R(Z, \eta)}{\delta Y_{k}} \mid Z, R>0\right)=\int_{\eta^{\prime}(Z)}\left[\frac{\delta R(Z, \eta)}{\delta Y_{p}}-\frac{\delta R(Z, \eta)}{\delta Y_{k}}\right] \cdot \frac{g(\eta) d \eta}{P_{R}(Z)}
$$

Substituting into the above equation and using the restriction (4.0) leads to

$$
E\left(\frac{\delta R}{\delta Y_{p}}-\frac{\delta R}{\delta Y_{k}} \mid Z, R>0\right)=\int_{\eta^{\prime}(Z)} 1 \cdot \frac{g(\eta) d \eta}{P_{R}(Z)}=1 .
$$

Thus, our answer to the first problem is to exploit the fact that since the restriction (4.0) is true for all $\eta$, it carries over to the expected value over $\eta$ of $(4.0)$.

Estimates of the left-hand side of (4.4b) are required to use (4.5) as the basis of a test. We work with the conditional expectation function

$$
\bar{R}(Z) \equiv E(R(Z, \eta \mid Z, R>0))=\int_{\eta^{\prime}(Z)} R(Z, \eta) \frac{g(\eta) d \eta}{P_{R}(Z)}
$$

which can be estimated given that $R$ and $Z$ are all observable. Specifically, we work with the derivatives of the conditional expectation function $\bar{R}(Z)$. Because selection into the sample with $R>0$ is not random, the income derivatives of $\bar{R}(Z)$ may not satisfy the restriction (4.5). However, we correct the derivates for sample selection bias using the method developed by Altonji (1993). We begin by differentiating (4.6) with respect to $Y_{j t}(j=p, k)$, obtaining

$$
\frac{\delta \bar{R}}{\delta Y_{j t}}=E\left(\frac{\delta R}{\delta Y_{j t}} \mid Z, R>0\right)+A_{j}^{2}(Z)+A_{j}^{3}(Z),
$$

In (4.7), $A_{j}{ }^{2}$ is 


$$
A_{j}^{2}(Z)=R\left(Z, \eta^{*}(Z)\right) \frac{g\left(\eta^{*}(Z)\right)}{P_{R}(Z)} \frac{\delta \eta^{*}(Z)}{\delta Y_{j t}}=0
$$

by virtue of the fact that on the boundary transfers are 0 . The term $\mathrm{A}_{\mathrm{j}}{ }^{3}$ is more problematic.

$$
\begin{aligned}
A^{3}(Z) \quad & =\int_{\eta^{*}(Z)} R(Z, \eta)\left[\frac{\delta}{\delta Y_{j t}}\left(\frac{g(\eta)}{P_{R}(Z)}\right)\right] \\
& =\int_{\eta^{*}(Z)} R(Z, \eta) \frac{g(\eta)}{P_{R}(Z)}\left[-\frac{\delta P_{R}(Z) / \delta Y_{j t}}{P_{R}(Z)}\right]
\end{aligned}
$$

The term in brackets does not involve $\eta$ and may be taken outside the integral. This fact and (4.6) imply

$$
A_{j}{ }^{3}(Z)=\frac{-\delta P_{R}(Z) / \delta Y_{j t}}{P_{R}(Z)} \bar{R}(Z)
$$

Thus

$$
\frac{\delta \bar{R}}{\delta Y_{j t}}=E\left(\frac{\delta R}{\delta Y_{j t}} \mid Z, R>0\right)+A_{j}^{3}(Z),
$$

where the term $A_{j}{ }^{3}(Z)$ is given by the previous equation. Since $\delta P_{R} / \delta Y_{k t}<0$ and $\delta P_{R} / \delta Y_{p t}>0$, the term $A_{k}{ }^{3}$ is positive and $A_{p}{ }^{3}$ is negative. Fortunately, one can estimate $A_{j}{ }^{3}(Z)$ by first estimating $P_{R}(Z)$ from data on an indicator variable for $R>0$ and $Z$ and then substituting the estimate of $P_{R}(Z)$, the estimate of $\vec{R}(Z)$, and the associated estimates of the derivatives $\delta P_{R} / \delta Y_{j t}$ into (4.10). Consequently, our estimator of the transfer-income derivatives is given by

$$
E\left(\frac{\delta R(Z, \eta)}{\delta Y_{j t}} \mid Z, R>0\right)=\frac{\delta \bar{R}(Z)}{\delta Y_{j t}}-A_{j}^{3}(Z)
$$

and the estimator of the difference in the derivatives with respect to $Y_{p t}$ and $Y_{k t}$ is

$$
\Delta E\left(\frac{\delta R(Z, \eta)}{\delta Y_{j t}} \mid Z, R>0\right)=\frac{\Delta \delta \bar{R}(Z)}{\delta Y_{j t}}-\Delta A_{j}^{3}(Z),
$$


where we replace the terms on the right-hand side with sample estimates and $\Delta F_{j}()$ is $F_{p}()-F_{k}()$, i.e., the difference operator, for any function $F_{j}()$. We may test the restrictions on the derivatives of $R$ with respect to $Y_{p}$ and $Y_{k}$ by comparing the sample estimate implied by (4.12b) to 1 for various values of $Z$. An Empirical Formulation

Let $\theta_{1}$ denote the parameters of the function $\bar{R}(Z)$. We estimate these parameters by running the following least squares regression on the sample for which $\mathrm{R}>0$ :

$$
R=\bar{R}\left(Z ; \theta_{1}\right)+u
$$

where $u$ is uncorrelated with $Z$ because $\bar{R}\left(Z ; \theta_{1}\right)$ is the conditional expectation of $R$. In practice, we use a flexible specification for $\bar{R}\left(Z ; \theta_{1}\right)$. We estimate $P_{R}(Z)$ using a probit model with a flexible specification $h\left(Z, \theta_{2}\right)$ for the probit index:

$$
P_{R}(Z)=\Phi\left(\frac{h\left(Z, \theta_{2}\right)}{\sigma}\right)
$$

where $\Phi()$ is the standard normal CDF and $\theta_{2}$ is the parameter vector of the probit index function.

Inference is complicated by the fact that the estimators $\hat{\theta}_{1}$ and $\hat{\theta}_{2}$ are correlated, and the derivative estimators are a complicated nonlinear function of both. Furthermore, one must account for the fact that the samples used to estimate $\hat{\theta}_{1}$ and $\hat{\theta}_{2}$ contain more than one observation from some families, and heteroscedasticity is likely to be present in (4.13). While one can use the "delta method" to derive the distributions of

$$
E\left(\frac{\delta R(Z, \eta)}{\delta Y_{p t}} \mid Z, R>0 ; \hat{\theta}_{1}, \hat{\theta}_{2}\right), E\left(\frac{\delta R(Z, \eta)}{\delta Y_{k t}} \mid Z, R>0 ; \hat{\theta}_{1}, \hat{\theta}_{2}\right), \text { and } \Delta \mathrm{E}\left(\frac{\delta \mathrm{R}(\mathrm{Z}, \eta)}{\delta \mathrm{Y}_{\mathrm{jt}}} \mid \mathrm{Z}, \mathrm{R}>0 ; \hat{\theta}_{1}, \hat{\theta}_{2}\right) \text { from }
$$

the asymptotic joint distribution of $\hat{\theta}_{1}$ and $\hat{\theta}_{2}$, the approximation may not be reliable. Consequently, we rely on a bootstrap procedure to estimate the standard errors of these derivatives for various values of $Y_{p t}, Y_{k t}$, and $X$ and for the sample average of the derivatives over the distribution of $Z$ 
for those who receive transfers. ${ }^{19}$ To simply the notation, we refer to these derivatives as $E \delta R / \delta Y_{p t}$, $E \delta R / \delta Y_{k t}$, and $\Delta E \delta R / \delta Y_{j . t}$

\section{Effects of measurement error in $\mathrm{R}$ and in whether $\mathrm{R}>0$}

Presumably, some respondents fail to report their receipt of transfers and some who do misreport the amount received. Let $R^{*}$ be the observed transfer amount. Suppose

$$
R^{*}=I \text { e R, }
$$

where I and e are random variables. Assume first that $I$ is a Bernoulli random variable equal to $I$ with fixed probability $\mathrm{p}_{\mathrm{I}}$ and 0 with probability $\left(1-\mathrm{p}_{\mathrm{I}}\right)$. Assume second that $\mathrm{e}$ is a positive random variable that is independent of $R$ with a mean of conditional on $R>0$. This measurement model says that the probability of reporting 0 when $R>0$ is independent of $R$, and that the variance of the reporting error when $\mathbf{R}>0$ is proportional to the level of $\mathbf{R}$. Both assumptions seem natural.

The Appendix shows that random reporting error in transfers of this type has no effect on our tests if $\overline{\mathrm{e}}=1$, even if a fraction of individuals who receive transfers fail to report them $\left(\mathrm{p}_{1}<1\right){ }^{20}$ (Tobit estimates would be biased in this case. $)^{21}$ If those who receive transfers tend to understate the size of the gifts $(\overline{\mathrm{e}}<1)$ then the derivative estimator will be biased downward by the factor $(1-\overline{\mathrm{e}})$ and the test will be biased against the altruism hypothesis. However, it turns out that $\overline{\mathrm{e}}$ would have to be far below one to square the estimates of the difference in derivatives with the prediction that they will equal 1. We conclude that measurement error is an unlikely explanation of the findings reported below.

\footnotetext{
${ }^{19}$ We divide the sample by the number of observations from each extended family, lumping together the handful of observations from families with 8,9 , or 10 observations. Let $\mathrm{Nj}$ be the number of families with $\mathrm{j}$ observations. For each $\mathrm{j}$ we draw with replacement from the sample until we obtain a new sample of $\mathrm{Nj}$ families. Our sample for each bootstrap replication is then the combination of the samples drawn for each $\mathrm{j}$. We then implement the derivative estimator. We performed 125 bootstrap replications and computed standard errors from the 10 th and 90 th percentile values assuming that estimator has a normal distribution. In Tables 6 and 7 we evaluate the derivatives at various points. In the bootstrap replications we always use the distribution of the original sample to determine the points (such as the mean) at which to evaluate the derivatives.

${ }^{20}$ One may easily extend the analysis in the appendix to show that if the probability of a reporting a transfer is a positive function of the transfer amount, then the difference in derivatives be positively biased.

${ }^{21}$ Blundell and Meghir (1987) discuss and provide additional references to papers using a "double hurdle" model in which $R$ has a Tobit structure, $e$ is 1 in all cases, and $I$ is an independent probit.
} 


\section{Data}

This section discusses the sample and then considers the construction and quality of our key variables.

\section{1 The Sample}

Our data come from the 1988 Panel Study of Income Dynamics (PSID) which includes a special supplement on transfers between relatives. ${ }^{22}$ Using the PSID overcomes a key problem in the study of intergenerational transfers, namely obtaining reliable data on the budget constraints of both parents and adult children. Our matched sample of parents and their children were 1968 PSID families who are heads of household or wives in the 1988 study. Only about 2 percent of the kids were students in 1988. We have annual data on the income and family composition of the households in which these individuals reside. We are also able to make use of information on assets, health status, income, and other variables that were collected in years before 1988 . Those 1988 households containing heads or wives who were children in the 1968 study are matched to the 1988 households of their parents. An observation consists of one such matched pair. Given that a child's mother and father may be in separate households, each child may appear in one or two records. Parents with multiple children appear in as many records as they have respondent children. The effective sample for most of the multivariate analyses consists of 3402 parent-child pairs, including 687 pairs with positive transfers. ${ }^{23}$

\subsection{The Transfer Data}

The information on $\mathbf{R}$ and whether $\mathbf{R}$ is positive is based on the following question:

\footnotetext{
22 Other recent papers using the newly released PSID data include Altonji et. al. (1992b), Hill (1993), Ionnides and Kan (1993), Pollak (1994), Shoeni (1992) and (1993). We also make limited use of the wealth data from the 1989 wave of the PSID.

23 The distribution of parent household records by number of children is summarized in the table below.

\begin{tabular}{|c|c|c|c|c|c|c|c|c|c|c|}
\hline \multirow[b]{2}{*}{ \# of Kids } & \multirow[b]{2}{*}{1} & \multicolumn{9}{|c|}{ Parent household observations by number of independent kids in PSID } \\
\hline & & 2 & 3 & 4 & 5 & 6 & 7 & 8 & 9 & 10 \\
\hline obs. & 644 & 454 & 235 & 135 & 60 & 27 & 11 & 7 & 0 & 1 \\
\hline
\end{tabular}

That is, 644 parent households have been matched to only 1 child, 454 that have been matched to 2 children, etc.. The sample contains 3018 children who are matched to one parent household and 192 children who are matched to two parent households.
} 
(1) During 1987, did (you/your family living here) receive any loans, gifts, or support worth $\$ 100$ or more from your parents? About how much were those loans, gifts, or support worth altogether in 1987 ?

Several points about the transfer data deserve mention. First, the question specifically refers to loans. Nonetheless, we treat the responses as transfer measures since we have no evidence on the fraction of the transfers that are actually loans. In this regard, Altonji et. al. (1992b) find that transfers are no more likely to be reported if the child had become a new homeowner between the 1986 and 1987 surveys or between the 1987 and 1988 surveys. Second, in the interest of simplicity we ignore the $\$ 100$ threshold in the question, although we doubt that this makes much difference. ${ }^{24}$ Third, we have little direct information on the quality of the data. Presumably, the fact that the question directly asks about help from parents is an advantage over questions that do not specify the relationship. ${ }^{25}$ The incidence of money transfers is higher than in most other studies. ${ }^{26}$ We believe that there is substantial measurement error in the transfer reports, but, to repeat, our derivative estimator is robust to random failure to report transfers and to random variation in the fraction of transfers that households report.

\subsection{Income And Wealth Measures}

We generally use family income net of asset income in 1987 as our measure of current income of the parents and the child $\left(\mathrm{Y}_{\mathrm{pt}}, \mathrm{Y}_{\mathrm{kt}}\right)$. We exclude asset income because it may be affected by prior transfers, but control for assets and permanent family income (including asset income separately.) We also use two alternative measures of permanent income $Y_{p}$ of the parents and $Y_{k}$ of the kids. Both are based on the regression model

$$
\log \left(Y_{i t}\right)=X_{\text {yit }} \beta+e_{i t}
$$

\footnotetext{
${ }^{24}$ The derivative estimator may easily be modified to take this threshold into account by subtracting $\$ 100$ from the reported transfers prior to estimation (see Altonji, 1993). This would have no effect on the uncorrected derivative estimates in columns 1 and 3 of Table 6 and 7 and lead to only a small change in the corrected derivative estimates.

${ }^{25}$ In (Altonji et. al. 1992a) we use the fact that the parents provide information on transfers given to others to check on the information provided by the children. The parental responses suggest a lower incidence of transfers. We argue that the fact that the question about money help provided to others does not identify the specific relationship to the recipient leads to underreporting.

${ }^{26}$ See Dunn (1993) for a recent survey.
} 
where $Y_{\mathrm{it}}$ is the family income of person $\mathrm{i}$ in year $\mathrm{t}$ and the vector $\mathrm{X}_{\mathrm{ytt}}$ consists of a fourth order polynomial in age, a set of marital status dummies, year dummies, and counts of number of children

The first measure assumes that $e_{i t}=v_{i}+u_{i t}$, where the serial correlation in $u_{i t}$ is assumed to be sufficiently weak to be ignored in computing permanent income. We first estimate the parameter $\beta$ by OLS from gender-specific OLS regressions using all observations in which the person was a head or wife. ${ }^{27}$ We estimate $v_{i}$ as the mean of the residuals from the regression for each person. We obtain our first measure of permanent income for parents by adding the estimate of $v_{i}$ to the prediction from the regression for a person who is aged 40 , married, with no children in 1988 and taking the antilog. ${ }^{28}$ We call these measures $Y_{p}$ and $\bar{Y}_{k}$ where the "bar" reflects the fact that they are basically time-averages of current and past income adjusted for demographic variables and time.

For the second measure, we model $\mathrm{e}_{\mathrm{it}}$ as a third order autoregressive process with coefficients that depend on a third order polynomial in age Age $_{\text {it }}$ of person $\mathrm{i}$ in year $\mathrm{t}$ :

$$
e_{i t}=\left[1, \text { Age }_{i t} \text { Age }_{i t}^{2}, \text { Age }_{i t}^{3}\right] \gamma_{1} e_{i t-1}+\left[1, \text { Age }_{i t} \text { Age }_{i t}^{2}, \text { Age }_{i t}^{3}\right] \gamma_{2} e_{t t-2}+\left[1, \text { Age }_{i t} \text { Age }_{i t}^{2}, \text { Age }_{i t}^{3}\right] \gamma_{3} e_{i t-3}+u_{i t}
$$

where $\gamma_{1}, \gamma_{2}$ and $\gamma_{3}$ are $4 \times 1$ vectors of parameters and $u_{i t}$ is serially uncorrelated. We estimate $\beta$ from (5.1) using OLS and estimate $\gamma_{1}, \gamma_{2}$, and $\gamma_{3}$ using the OLS residuals from the sample estimate of $(5.1){ }^{29}$ We then use the chain rule of forecasting to forecast future values of $e$ for the periods $t+1$ to $t+6$, combine the forecasts into an index with weights that decline geometrically at rate $1 / 1.07$ and sum to 1 , add the index to the prediction based on the estimate of (5.1) for a person who is aged 40 ,

\footnotetext{
${ }^{27}$ We estimate separate models for men and women and use all those heads of household and wives in the PSID who have valid data in a given year rather than only those individuals in our matched intergenerational sample.

28 We included all years of data in which respondents were either a head of household or the wife of the head. Consequently, if a divorce occurs, the data for women include observations from the years in which she is married as well as the later years. Note, however, that the regressions control for marital status. An alternative would be to use family income in the years since the most recent change in marital status. The measures $\hat{Y}_{p}$ and $\hat{Y}_{k}$ based on the autoregressive model discussed below do not place any weight on values of $\mathrm{e}_{\text {it }}$ that are more than two years in the past, and, consequently, are less sensitive to this issue.

29 The samples used to estimate the autoregression for it are restricted to observations for which 3 lags of income are available. Lagged family income residuals cannot be constructed for children who became heads or wives for the first time in 1986 or 1987 or for whom family income is missing for other reasons. To avoid dropping these observations we set the 1985 value of it to the 1986 value (if available) or 1987 if not. We set missing data for 1986 equal to the 1987 value.
} 
married, with no children in 1988, and take antilogs. We call these measures $\hat{P}_{p}$ and $\hat{Y}_{k}$. They allow time dependence in the stochastic income component to depend on age and place more weight on the recent past than the time-averaged measures

The quality of the permanent income measures deserves discussion. The minimum number and 5 th percentile of the number of observations used to construct $\bar{Y}_{p}$ are 10 and 21 respectively. The 5th, 50th, and 90 th percentiles for the number of observations used to construct $\vec{Y}_{k}$ are 1,9 , and 18 . The fact that these measures are averaged from several years of data suggests that transitory income and measurement error will have only a minor effect on them. ${ }^{30}$

Our measure of assets of the parents is based on the 1984 wealth supplement to the PSID, which is the most recent year prior to 1988 in which detailed information on assets was collected. Since this variable refers to the wealth of the head and wife (if present) of the individual's 1984 household, we interact this variable with a dummy equal to 0 if the household head changed since 1984 and 1 otherwise and add the dummy variable to the list of controls. We construct the asset measure and a change in household head dummy for the child household in the same way. We also explore the issue of measurement error by experimenting with data from the 1989 wealth supplement.

In some of our estimation we use the average of permanent incomes of siblings who are heads or wives in the PSID as control for the resources of siblings. ${ }^{31}$ Since permanent family income may reflect asset income from past transfers, we also experiment with measures of permanent labor earnings of the husband and wife. Table 1 presents the unweighted means and standard deviations of selected variables for our sample and for the subsets with and without positive transfers. The means of age are 30.5 for the children and 58.7 for the parents. One implication of our model of the timing of transfers is that the transfer probability should fall with age of the child as earnings rises relative to permanent

\footnotetext{
${ }^{30}$ Note that the income from assets, annuities, pensions is reflected in our permanent income measures. The annuity value of assets that do not generate an income stream, such as a home, will not be reflected in the permanent income measures but will be reflected in controls for wealth.

31 When no independent siblings are present in the sample, we set the measure of sibling income to 0 . We control for whether or not independent siblings are present with a dummy variable. All specifications include a control for the inverse of the number of siblings, whether or not they are independent PSID households. Not surprisingly, transfers to a given child are negatively related to the number of siblings (see Altonji et. al., 1992a).
} 
income. This is consistent with the table as well as with the multivariate probits (not shown). Only 2.9 percent of the children who were heads of household and reported a positive transfer in 1987 were students at the time of the 1988 survey. The comparable percentage for wives is 6 percent. The percentages who were students in 1987 is similar, so few of the transfers would appear to be related to recent schooling expenditures.

\section{Results}

This section is divided into four subsections. Section 6.1 presents descriptive statistics on the distribution of transfers. Sections 6.2 and 6.3 present Probit and Tobit models of the transfer probability and amount. Section 6.4 presents estimates of the transfer-income derivatives based on the estimator (4.12a) and (4.12b) for our basic specification. Section 6.5 shows that these results are robust to a large number of changes in the specification, data, and estimation method. Section 6.6 discusses the source of our findings more broadly.

\subsection{The Distribution of Transfers}

Table 2 reports the mean probability of a transfer and the mean, standard deviation, and 5 th, 25th, median, 75th, and 95th percentiles of the distribution of positive transfers. It also reports corresponding statistics for the ratio of the transfer amount to the income of the parents and the income of the child. The parents are either the parents of the husband or the parents of the wife, depending upon whether the husband or the wife was a child in the original 1968 PSID sample. Tables 2 and 3 aggregate transfers received from and given to parents living separately, so each person with living parents appears only once in the sample used to compute these tables. ${ }^{32}$

The probability that $R$ is positive is .23 . The overall mean transfer is $\$ 421$ (in 1988 dollars) and the mean and median of the positive transfers are $\$ 1810$ and $\$ 500$. When $R$ is positive, the median and 95th percentile of the ratio of $R$ to the child's 1988 income are .022 and .372 for the sample with

\footnotetext{
32 In practice, this makes little difference. We attempt to approximate a representative sample of independent children with one or more living parents by using the 1988 person weights in Table 2 and 3 . Statistics reported in the paper are based on unweighted samples unless otherwise indicated. The multivariate analyses are unweighted. The sample for Tables 2 and 3 is slightly largely than the samples for the other tables because it includes observations that are missing data on one or more variables needed for the multivariate analyses. The discrepancy between Table 1 and Table 2 in the probability of a transfer (.202 versus .233) reflects aggregation across parents and weighting in Table 2.
} 
positive income. The median and 95 th percentile of the ratio of $\mathrm{R}$ to the parents' 1988 income are .014 and .169

Table 3 presents weighted estimates for the matched sample of the probability of transfers and the mean amount given a positive transfer by permanent income decile of the parents and child using $\overline{\mathrm{Y}}_{\mathrm{p}}$ and $\bar{Y}_{\mathrm{k}}$ as the measures. Mean income for each decile is also shown. The bottom row shows that the probability of a transfer from parents to kids changes little with kid's income, although it is interesting to note that children in the highest income decile have the highest probability of receiving a transfer $(.297)$.

According to the table, the probability of a transfer is negatively related to the child's income holding the parents' income decile constant. The bottom row shows that there is a weak positive correlation if one does not hold the parents' decile constant. The transfer amounts have a weak negative relationship to the child's income when the parents' income is held constant. However, the bottom row shows that they increase substantially with $\mathrm{Y}_{k}$ when parents' income is not held constant. Evidently, the strength of the relationship between the child's income and the transfer amount is exaggerated by a failure to control for parental income. ${ }^{33}$

Holding the child's income constant, parents' income bears a positive relationship to the transfer probability and, in the case of a positive transfer, to the transfer amount. The last column shows that the probability of a transfer rises from .110 in the lowest decile of $Y_{p}$ to .228 in the 5 th decile to .344 in the top decile. The mean of the transfers also rises with parental income, from $\$ 452$ in the lowest decile to $\$ 3206$ in the highest The relationship appears to be stronger than the relationship between transfers and the child's income. However, the increase in transfer amounts as the parents' income increase holding the child's constant is only a small fraction of the increase in the parent's income, which has a mean of 22,764 in the first decile and 127,674 in the 10th decile.

Table 3 a repeats Table 3 , but with permanent income replaced by current income. The results are qualitatively similar to those for permanent income. The main difference is a stronger negative

33 We noted earlier that most previous studies use proxies for parental income that may not provide an adequate control. 
relationship between the child's current income and the transfer probability. This partially reflects the fact that our permanent income measure adjusts for age, while income does not.

One way to summarize Tables 3 and $3 a$ is to regress the cell means for the transfer amounts against the cell means for the parents' income and the child's income. Using the permanent income measures in Table 3, the coefficient (uncorrected OLS standard error) on parents' income is .0322 $(.007)$ and the coefficient on the child's income is $-.005(.009)$. Using Table $3 a$, the coefficient on parents' current income is $.018(.007)$, whereas the coefficient on the child's income is $.005(.010)$. Thus, inspection of Tables 3 and $3 a$ and the summary regressions suggest that $\Delta \delta E R / \delta Y_{j}$ is much closer to 0 than the value of 1 implied by altruistic preferences. There are, of course, many problems with these simple cross tabulations. However, the basic results are qualitatively consistent with what we obtain below using the Tobit estimator and the derivative estimator based on (4.12b).

\subsection{The Effects of Income and Wealth on the Probability of a Transfer.}

Column 2 of Table 4 reports Probit estimates of the effects of the current and permanent income of the child and the parents on the probability that the child receives money from the parents and a detailed set of controls, using $\bar{Y}_{p}$ and $\bar{Y}_{k}$ as the measures of $Y_{p}$ and $Y_{k}$. In column 3 we use $\hat{Y}_{p}$ and $\hat{Y}_{k}$ as the measure with little effect on the results. Since the relationship between transfers and income is likely to be nonlinear, the model contains cubics in $Y_{p t}$ and $Y_{k t}$, cubics in the measures of $Y_{p}$ and $Y_{k}$, the product of $Y_{p}$ and $Y_{k}$, cubics in the assets of both parties and the product of the assets. The income and wealth variables are measured in $\$ 1,000 \mathrm{~s}{ }^{34}$

Column 2, row 7 of the table reports that, for this specification, the sample mean of the derivative of the transfer probability with respect to $Y_{k t}$ is -.0021 , which implies that a $\$ 10,000$ increase in the current family income of the child will lower the odds of a transfer by .021 . Rows 8,9 , and 10 report the predicted transfer probability evaluated at the median, 20th percentile, and 80th percentile of

\footnotetext{
${ }^{34}$ Rows (1), (6), (11), and (16) report the probit coefficient (standard error) on $Y_{k t}, Y_{p t}, Y_{k}$, and $Y_{p}$, respectively, for a model including only the linear terms in these variables. In column (2) the coefficient (standard error) on $Y_{k t}$ is $-.0044(.0021)$, the coefficient on $Y_{p t}$ is $.0036(.0011)$, the coefficient on $Y_{k}$ is $-.0021(.0016)$, and the coefficient on $Y_{p}$ is $.0075(.0013)$.
} 
$Y_{k t}$, the median of $Y_{p}, Y_{k}$, and $Y_{k t}$, and the mean of all other variables. The probability is 145 at the median of $Y_{k t}, .176$ at the 20 th percentile and .116 at the 80 th percentile. Rows 8,9 , and 10 report a similar set of calculations on the effects of parental income $Y_{p t}$ showing that the transfer probability is .127 at 20th percentile of $\mathrm{Y}_{\mathrm{pt}}$ and .183 at the 80th percentile.

An increase in the permanent income of the child from the 20 th to the 80 th percentile has a small negative effect on the probability. On the other hand, a comparable increase in the permanent income of the parents raises the transfer probability from .096 to .197 , which is about double the effect of parents' current income. In column l we report estimates which exclude current income measures and wealth.

These confirm a strong positive effect of the permanent income of the parents and a significant negative effect for the permanent income of the child on the odds of a transfer. ${ }^{35}$

\subsection{Tobit Estimates of the Effects of Income and Wealth on Transfers}

In Table 5 we use Tobit models to analyze the effect of income and wealth of parents and kids on the magnitude of transfers. The specifications in the columns correspond to those in Table 4 .

Column 2 includes current income, permanent income, and wealth using $\bar{Y}_{p}$ and $\bar{Y}_{k}$ as the measures of $Y_{p}$ and $Y_{k}$. In column 3 we obtain similar results using $\hat{Y}_{p}$ and $\hat{Y}_{k}$ as the measures. Since the Tobit model assumes additive separability between $Z$ and $\eta$, the derivatives of the Tobit index with respect to $Y_{k t}$ and $Y_{p t}$ provide estimates of $E\left(\delta R(Z, \eta) / \delta Y_{k t} \mid Z, R>0\right)$ and $E\left(\delta R(Z, \eta) / \delta Y_{k t} \mid Z, R>0\right)$, respectively. When we exclude the nonlinear income terms, the Tobit index coefficients are the current income

35 Columns 2 and 3, rows 23-25 report that the partial effect of the child's wealth is essentially 0 , while an increase in parental wealth from the 20 th to the 80 th percentile raises the transfer probability from 120 to 190 (col. 2 rows 28-29) Since assets of the kid, particularly early in the life cycle, may be heavily influenced by previous transfers, the coefficient on child's assets is probably biased upward (toward a positive value) in the likely event that there are unobserved, serially correlated factors influencing transfers. If parents accumulate assets in anticipation of providing transfers to children, then coefficient on parents' assets may be overstated in absolute terms. Also keep in mind that our measures of permanent income include income from assets, which makes it a bit difficult to interpret the asset variable separately. In column 4 we report estimates after substituting current earnings and permanent earnings of the head and wife (based on the fixed effect specification) for family income and adding cubic specifications for net assets of the parents and the kids (measured in 1984). For the parents the effects of assets are larger when earnings are used, with a 20th to 80th percentile shift in wealth associated with a 097 increase in the transfer probability. For the children, the effect remains very small but becomes positive. In column 5 we drop the current earnings measures and obtain results for permanent eamings analogous to those in column 1 for the permanent income. The effect of the child's assets becomes negative. The coefficients on the child's assets in row (11) is based on a linear specification and is not statistically significant. However, the coefficients of the cubic specification in child's assets are jointly significant, and the probability of a transfer falls from .155 for a child in the 20th percentile of the wealth distribution to 149 for a child in the 80 th percentile. 
derivatives. The Tobit index coefficients and standard errors for $Y_{k t}$ and $Y_{p t}$ based on a linear specification are $-.023(.011)$ and $.009(.003)$ (rows 5 and 13). When we include the nonlinear terms, the estimate of $E \delta R / \delta Y_{k t}$ is -.072 when evaluated over the distribution of $Y_{k t}$ (column 2, row 6). The corresponding estimate of $E \delta R / \delta Y_{p t}$ is .024 (row 14). ${ }^{36}$ The difference between these two derivatives is only .096 , which is far below the value of 1 implied by the altruism theory.

Using the equation with cubics in the income terms we find that the 20th to 80th percentile differential in $\mathrm{R}$ (including 0 transfers) is $\$-319$ for $\mathrm{Y}_{\mathrm{kt}}$ (not reported). The size of the transfers (conditional on being positive) decline by $\$ 459$ (not reported). As one would expect from the derivatives in rows 5 and 6 , a 20th to 80th percentile increase in $\mathrm{Y}_{\mathrm{pt}}$ has only a small positive effect on transfer amounts, regardless of whether one conditions on positive transfers. ${ }^{37}$

To summarize, the multivariate Tobit models results basically confirm the simple crosstabulation in Table 3. Although there are many objections to the use of the Tobit model in the present context, particularly under the null hypothesis of the altruism model, the Tobit results are also basically consistent with the derivative estimator for nonlinear models, to which we now turn.

\subsection{Results for the Derivative Estimator for Nonlinear Limited Dependent Variables Models}

Table 6a reports the derivatives of transfers with respect to current nonasset income $Y_{p t}$ and $Y_{k t}$ of the parents and kids based on the estimator in Section 4. We use $\bar{Y}_{p}$ and $\bar{Y}_{k}$ as the measures of permanent income. In Table $6 \mathrm{~b}$ we report results using $\hat{Y}_{\mathrm{p}}$ and $\hat{Y}_{k} \cdot{ }^{38}$ Columns 1 and 3 of tables

\footnotetext{
${ }^{36}$ The average of the derivatives is evaluated using the full sample used to estimate the Tobit model.

${ }^{37}$ While our main interest is in the effects of current income controlling for permanent income and asset, the table also reports the effects of $Y_{k}$ and $Y_{p}$ as well as the asset variables. In the linear case the Tobit coefficient and standard error for $Y_{k}$ is $-.010(.008)$ (row 9). The negative partial effect of the child's permanent income switches from a small negative value in the linear specification to a small positive effect in the nonlinear model (compare rows 9 and 10 ). In the linear case, the coefficient on $Y_{p}$ is $.046(.006)$. The average derivatives with respect to $Y_{p}$ of the Tobit index, the average transfer amount including 0 transfers, and the average positive transfer are $.054, .0071$, and .0098 . The Tobit coefficients imply that a 20 th to 80 th percentile value increase in $Y_{p}$ raises the average transfer amount (including 0 transfers) by $\$ 332$ and raises the size of the average positive transfer by 376 . (Not reported in the Table). The asset coefficients imply that the average change in the Tobit index with respect to a $\$ 1000$ increase in the child's wealth is 17.5 , which has the wrong sign, but is small. The corresponding derivative with respect to parents' assets is 14.3 .

${ }^{38}$ Our basic specification of (4.13) and (4.14) contains cubics in the nonasset incomes of the parents and child with a full quadratic interaction, cubics in the assets of both parties and the product of the assets, and cubics in the $Y_{p}$ and $Y_{k}$ and the
} 
reports the uncorrected derivatives $\delta \vec{R}(Z) / \delta Y_{p t}$ and $\delta \bar{R}(Z) / \delta Y_{k \ell}$. Columns 2 and 4 report the corrected derivatives $E \delta R / \delta \mathrm{Y}_{\mathrm{pt}}$ and $E \delta \mathrm{R} / \delta \mathrm{Y}_{\mathrm{kt}}$ based on (4.12). (The sample selection correction factors are the terms defined in equation ( $4.10 \mathrm{a})$.) Column 5 reports the difference $\Delta E \delta R / \delta$ Yjt between the estimates of $E \delta R / \delta Y_{p t}$ and $E \delta R / \delta Y_{k t}$ and the estimates of the difference between these two derivatives evaluated at various points. The results indicate that the correction factors are often substantial relative to the uncorrected derivatives and almost always have the expected sign, with $A_{p}{ }^{3}(Z)<0$ and $A_{k}{ }^{3}(Z)>0$.

In row (1) we take the sample mean of all the terms evaluated at the values of $Z$ for each observation in the sample with positive transfers. In row (2) we evaluate the derivatives at the sample means of all variables. The corrected estimates of $E \delta R / \delta Y_{p t}$ and $E \delta R / \delta Y_{k t}$ evaluated at the sample means are $.035(.015)$ and $-.088(.036)$. The implied value for $\Delta E \delta R / \delta Y_{j t}$ is $.123(.038)$, which is far below 1. The corresponding estimate using the alternative measures of permanent income in Table $6 \mathrm{~b}$ is .110 The sample average of $E \delta R / \delta Y_{p t}-E \delta R / \delta Y_{k t}$ is .089 (row l) although the standard error is relatively large. The largest estimate of the difference in derivatives is .164 , which we obtain when we use $\bar{Y}_{p}$ and $\bar{Y}_{k}$ as the controls for permanent income and evaluate the derivatives at the mean of $X$ and the 80th and 20th percentile values of $\mathrm{Y}_{\mathrm{pt}}$ and $\mathrm{Y}_{\mathrm{kt}}$ (respectively).

In summary, the difference in the derivatives of transfers with respect to the current incomes of the parents and child is about .1 rather than the value of 1 implied by the altruism model. The result reflects two basic facts about the PSID data that are also consistent with evidence from other data sets, such the NLS (See Dunn (1993) results and his survey of other studies.). First, the derivative of transfer amounts with respect to parents' current income (and permanent income) is relatively small. A small value is perfectly consistent with the theory and depends on the form of preferences and distribution of resources. However, altruism implies that in this case the derivative of the transfer amounts with respect to the child's income must be negative and large in absolute value. In fact, transfer amounts are not very responsive to the child's income. This basic fact does not appear to be the

product of $Y_{p}$ and $Y_{k}$. We include the dummies for missing asset data for parents, the child, and either the parents or the child. We include the same demographic controls used in the probit and Tobit models in Tables 4 and 5 . The detailed regression estimates and probit estimates underlying these estimates are available upon request. 
result of bias from selection into the sample with positive transfers, because our methodology corrects the effects of bias on the income derivatives.

In Table $7 \mathrm{a}$ and $7 \mathrm{~b}$ we drop the current income terms and report the derivatives with respect $\mathrm{Yp}$ and $Y_{k}$. Although the theory suggests that current income of the child, holding permanent income constant, is the relevant variable, there are some pragmatic reasons having to do with measurement error to look at the derivatives with respect to permanent income. Also, the size of these derivatives provides information about the extent to which differences in permanent income are mitigated through transfers. In Table $7 \mathrm{a}$, which is based on $\bar{Y}_{\mathrm{k}}$ and $\overline{\mathrm{Y}}_{\mathrm{p}}, E \delta \mathrm{R} / \delta \mathrm{Y}_{\mathrm{p}}$ is .037 at the sample mean with a standard error of .014 , while $E \delta R / \delta Y_{k}$ is -.017 with a standard error of .004 . It is also interesting to note that $E \delta R / \delta Y_{k t}(-.017$ in row 2 of Table $6 a)$ is substantially larger than $E \delta R / \delta Y_{k}$, while $E \delta R / \delta Y_{p}$ and $E \delta R / \delta Y_{p t}$ are very similar. This is consistent with the view that liquidity constraints are important for a substantial fraction of the younger households, but not important for older households.

The estimate of $E \delta R / \delta Y_{p}-E \delta R / Y_{k}$ is reported in column 5. At the sample mean this parameter is .053 with a standard error of .016 ; which is far below 1 . We obtain similar results using $\hat{Y}_{\mathrm{k}}$ and $\hat{\mathrm{Y}}_{\mathrm{p}}$ in Table $7 \mathrm{~b}$, and the results are not very sensitive to where the derivatives are evaluated. The flow of money transfers is only weakly related to the difference in the permanent incomes of parents and children.

It is interesting note that the negative signs for $\delta \mathrm{R} / \delta \mathrm{Y}_{\mathrm{kt}}$ and $\delta \mathrm{R} / \delta \mathrm{Y}_{\mathrm{k}}$ in Tables 6 and 7 contradict Cox's 1987 finding of a positive and significant effect of $Y_{k}$ on $R$. When we drop the control for $Y_{p}$ in the equation in Table 7a, we find that the OLS estimate of $\delta R / \delta Y_{k}$ is .0052 at the sample mean and the corrected estimate of $\delta \mathrm{R} / \delta \mathrm{Y}_{\mathbf{k}}$ is .0038 . Failure to control for parental income leads to an overstatement of the effects of children's income. In our case, the coefficient switches sign (although the coefficient is not significant). However, much of the difference between our results and Cox's is due to factors other than the fact that his data set does not contain a good measure of parental income. Dunn (1993) uses matched panel data from the NLS to construct permanent income measures of $Y_{p}$ and $Y_{k}$ and also finds that $Y_{k}$ has a negative sign in Tobit models. 


\subsection{Additional Experiments}

In this section we examine the sensitivity of the results to changes in the specification and estimation methods.

\section{Controlling for the Income of Siblings.}

One objection to these results is that we have not controlled for the income of other relatives to whom the parents may be altruistically linked. We added the average of $Y_{k}$ for siblings of the child who are in the sample, and found that this has almost no effect on the difference in the derivatives. ${ }^{39}$ Interactions With Number of Siblings:

In Appendix Table Al we report the income derivatives after adding interactions between the income variables and $1 /(1+$ number of siblings $)$ to the specification of (4.13) and (4.14). We also control for the level and the square of the average income of siblings in this specification. We exclude people who have siblings but do not have siblings who were PSID splitoffs. At the sample means the results are very similar to those in Table 6. At the sample means for all variables except number of siblings the difference in derivatives is 161 for only children and .113 for children with 3 siblings.

The decline in the difference in derivatives with the number of children has implications for some alternative theories of transfers. One possible explanation for the failure of the test of income derivatives is that it is costly for parents to differentiate among children. We have heard this point from many seminar participants, but we have not heard a good theoretical explanation for the costs. Although it seems ad hoc, one could simply add an "aversion to inequality in transfer amounts" argument to the parental utility function in our model. This would break the restriction that $\Delta E \delta R / \delta Y_{j t}$ must equal 1. It would also lower $E \delta R / \delta Y_{p t}$ because part of the increase in transfers would be wasted on rich children. A modification to the basic altruism model that is perhaps more appealing on theoretical grounds and has similar implications involves the following assumptions. The first is that

\footnotetext{
${ }^{39}$ Sibling income has a positive effect on transfers. In (Altonji et. al. 1992a) we control for family fixed effects and find that richer siblings are less likely to receive money transfers from parents and more likely to give money transfers to parents.
} 
children care deeply about how much their parents love them ${ }^{40}$. The second is that children are hurt if they feel that the parents prefer a sibling. The third is that children have imperfect information about the actual needs of their siblings. The fourth is that children make inferences about their parents' feelings for them based on the amount of help that they and their siblings receive, and parental transfers cannot be fully hidden from other siblings. If these assumptions are correct, then altruistic parents whose utility functions do not depend directly on transfers may choose not to differentiate much among their children when giving gifts. They will be concerned about the utility losses associated with the inferences that children draw about parental preferences from the differentiated gifts. This type of signaling model is qualitatively consistent with a number of facts. First, it implies that bequests, which are public, will be less sensitive to the relative incomes of siblings than intervivos transfers. The results of Wilhelm (1991) and Menchik (1980) show that bequests are evenly divided among children in most cases and insensitive to the relative incomes of the children. The results of Altonji et. al. (1992b) and Dunn (1993) show that transfers do depend on the relative incomes of siblings.

Since there is no information extraction problem in the case of only children, our finding that $\Delta \mathrm{E} \delta \mathrm{R} / \delta \mathrm{Y}_{\mathrm{jt}}$ is larger for only children is qualitatively consistent the theory. However, the fact that the difference is only . 161 even for only children and that the coefficient on parents' income is actually smaller for only children ( .017 versus .031 for persons with 3 siblings) suggests that costs of unequal treatment of children are only a minor part of the story.

\section{Interactions with Other Demographic Variables:}

We also investigated the possibility that the income derivatives depend on demographic variables that influence the probability of a transfer. In Appendix Table A-1 panel B we report derivative estimates for a specification in which we augment the model with interaction terms between income and assets and the probit index from the transfer probability model evaluated at the means of all income and asset variables and the values for each observation of all other variables. (We use an index because

\footnotetext{
${ }^{40}$ In the model in section $2 U\left(c_{k}\right)$ would depend on the child's belief about $\eta$, which are based on the parental behavior, including transfers given.
} 
there are too many demographic variables to consider interaction terms for each one.) The results show that the transfers-income derivatives are not very sensitive to the value of the transfer probability Measurement Error in Income:

We noted earlier that measurement error in current income of the parents and child will bias the results below the theoretical value of 1 . We investigated this issue by forming instruments for the level, square, cube and the interaction terms involving the parents' and child's nonasset income. The instrumental variables consist of powers of the income in 1986 which the parents and child report in the 1987 survey, the average of the siblings' reports of their parents' 1987 income, the square and cube of this average, and all other variables in the transfer equation (including all terms involving permanent income and assets). ${ }^{41}$ At the sample mean the estimate of the $E \delta R / \delta Y_{p t}$ is -.004 , while $E \delta R / \delta Y_{k t}$ is 145. Thus, the difference in derivatives is .149 . This is $35 \%$ higher than the estimate that ignores measurement error, suggesting that there is a substantial amount of measurement error in the current income measures. However, measurement error does not go very far in squaring the estimated values of the difference in derivatives with the value of 1.0 predicted by the altruism model.

\section{The Measure of Income}

Our results were not very sensitive to the use of alternative measures of current family income, including after tax family income, family income minus help from relatives, family income net of taxes and help from relatives, and total family income (including income from assets). ${ }^{42}$ (Results not reported)

\section{Measurement Error in Assets:}

The 1989 wave of the PSID contains a wealth supplement that is very similar to the questions asked in 1984. We have re-estimated the model substituting the 1989 measure for the 1984 measures.

41 The 1988 supplement on transfers asked about the income of parents. We set the average of the sibling report of parents to 0 and include a missing data dummy when the kid's reports of parental income are missing for all of the siblings from a given family who are in the matched sample. We estimated prediction equations using the full sample used to estimate the probit model for the probability of a transfer and inserted the predicted values of the income terms into the probit model (4.14) and the regression model (4.13) for positive transfer amounts. Such two stage approaches are usually inconsistent in nonlinear models but we do not have an alternative to it.

\footnotetext{
42 As noted above, the question about help from relatives is separate from questions about transfers in the 1988 transfer supplement.
} 
The estimate of $E \delta \mathrm{R} / \delta \mathrm{Y}_{\mathrm{pt}}-\delta \mathrm{R} / \delta \mathrm{Y}_{\mathrm{kt}}$ evaluated at the sample mean rises from .110 to 133 . When we form instruments for the current income variables and the 1989 asset measures using the instruments mentioned above along with the 1984 asset measures, at the sample means $E \delta R / \delta Y_{p t}$ is -.013 , which has the wrong sign but remains small. $E \delta R / \delta Y_{k t}$ is -.106 , and the difference is 119 when evaluated at the sample means. In summary, there is little evidence that measurement error in wealth and/or income has a large effect on the results.

\section{Sensitivity to Outliers, Functional Form for Transfers and Income, and Estimation Method:}

We noted earlier that the distribution of transfers is skewed to the right. We have re-estimated the model after excluding 35 cases of transfers in excess of $\$ 5,000$. The results in Table A-2, Panel A show that this has the effect of lowering the transfer-income derivatives by about 60 percent.

Since the heavy skewness in the transfer distribution may be affecting the robustness of our estimates, we have also estimated the conditional expectation function $\bar{R}(Z)$ by first estimating a regression model for the log of transfers and then using the parameter estimates and the estimated error variance of that model to compute $\bar{R}(Z)^{43}$. The result, reported in Appendix Table A2 Panel B, are close to but somewhat smaller than those in Table 6 , columns 2,4 and $5 .$.

The level of income is approximately log normal, so a few large values of income could have a large effect on our estimates, particularly since we use a polynomial form. We estimated $\bar{R}(Z)$ from a regression model for the log of transfers as the dependent variable after replacing the polynomials in the levels of the current income and permanent income with polynomials in the logs. Observations with nonasset income below $\$ 1,000$ excluded. The average of the difference in derivatives declines from .093 to .056 , and the difference in derivatives at the sample mean declines from .110 to 041 . (Table A-

\section{2, Panel C)}

As a final check, we used least absolute deviation regression (LAD) to estimate the conditional mean function on the grounds that LAD regression may be more robust even though it is an inconsistent

\footnotetext{
43 In going from the $\log$ regression model to the conditional expectation function (4.13) for the level of $R$, we assume that the error term in the log transfer equation is additive and has a log normal distribution. We then use the formula for the expectation of a lognormal random variable.
} 
estimator of the conditional mean function when errors are skewed. The income derivatives decline in absolute value. In summary, our basic conclusion that the income derivatives are small appears to be quite robust.

\subsection{Discussion of Findings}

Are there additional problems with the data and methods or modifications to the model that can reconcile the empirical results with altruistic preferences? One possibility is that respondents who report positive transfers on average report only 13 percent of the transfers they receive. (That is, $\overline{\mathrm{e}}$ on page (22) is .13) If one were to multiply average transfers of 1810 by $(1 / .13)$, one would conclude that average transfers are on average receiving 13,923 dollars per year, which seems far too high, particularly given that many parents have more than 1 child. Underreporting of transfer amounts may be able to explain a part of the gap between 13 and 1 , but it does not seem likely that it can explain all or even most of it.

A second issue is the consequences for our test of departures from optimality in the timing of transfers. We show in Section 2 that the timing of transfers is determinant if future income (or needs) are uncertain and credit markets are imperfect. It may be, however, that the utility loss from minor variation in the timing is small for families with relatively stable income streams. Even for these families the model in Section 2 describes how transfer flows are determined over a period of a time, and actual transfers should match the flow implied by the model if both are aggregated over a few years. However, some families may not make a transfer in the year we examine, and some may receive a transfer that is larger than what they receive in an average year over a period of 2 or 3 years (say).

Would such indeterminacy invalidate the test? We considered the case in which both the frequency of transfer flows and the size of each transfer are positively related to the average transfer flow. We also considered the case in which the frequency of transfer flows is independent of the average transfer flow. In both cases the transfer-income derivative test statistic derived in Section (4) 
will be greater than or equal to 1 if the altruism hypothesis is correct. Consequently, indeterminacy in the timing of transfers seems, if anything, to strengthen the rejection of altruism.

We also investigated whether random variation around the optimal division between transfers in period $t$ and bequests would affect the results. We investigated a model in which transfers $R(Z)$ in $t$ are equal to a positive random variable $q$ times the value implied by our model, and bequests equal the value implied by the model plus $(1-q) \beta(t) R(Z)$, where $q$ has mean $\bar{q}$ and $\beta(t)$ is a discount factor chosen so that present discount value of transfers plus bequests is not affected by $q$. In this case $\Delta E \delta R / \delta Y_{j t}$ will equal $\bar{q}$ under the null. Consequently, random variation around the optimal timing, with $\vec{q}$, equal to 1 , has no effect on our analysis. A very large departure from optimality would be required to rationalize an estimate of $\Delta E \delta R / \delta Y_{. t}$ of .13 with the altruism model ${ }^{44}$

If one accepts the results, it useful to ask what models are more consistent with them. One possibility is that preferences are altruistic, but parents know little about the incomes of their children. It is easy to show in a static model that this would reduce $E \delta R / \delta Y_{k t}$ in absolute value and reduce the difference in test statistics. However, given the estimates of $E \delta R / \delta Y_{p l}$, the parents would have to be almost completely ignorant of their child's current income for this explanation to work. ${ }^{45}$

A second possibility mentioned earlier is that efforts by parents to "tax" $\mathrm{Y}_{\mathrm{kt}}$ will distort the hours of work and effort decisions of children. This would appear to be an important issue if one takes our estimates of $E \delta R / \delta Y_{p t}$ of .03 to .05 seriously. These estimates imply that parental preferences are such that they would prefer to reduce transfers by .95 to .97 for each extra dollar of $Y_{k t}$. Thus, the disincentive effects may be a major constraint on parental behavior, particularly if children are not very concerned about the utility of their parents. (If parents and children have the same objective function

\footnotetext{
44 The introduction of the random timing factor $q$ is similar analytically to introducing the reporting error factor $\mathrm{e}$ in $\mathrm{R}$ in Appendix 1. The 1984 wave of the PSID has some limited information on expected inheritances which could be used to estimate the derivatives of bequests with respect to $Y_{p t}$ and $Y_{k t}$ holding the other variables constant. Unfortunately, there is no comparable transfer data in that year.

45 In Altonji et. al. (1992b) we studied consumption linkages with the extended family differences and we found that replacing family income with the component of income that is predictable based on schooling and 2 digit occupation actually strengthened the evidence against the joint hypothesis of altruistic preferences and operative altruistic links. This finding suggests that parents know quite a bit about the permanent incomes of their children, although it leaves open the possibility that they do not know much about current income conditional on permanent income.
} 
there would be no disincentive effects.) In view of our findings it would interesting to draw on the optimal taxation literature to conduct an analysis of how large the child's labor supply response would have to be to square our low estimates of $E \delta R / \delta \mathrm{Y}_{\mathrm{kt}}$ and $E \delta \mathrm{R} / \delta \mathrm{Y}_{\mathrm{pt}}$ with altruism. A third possibility is that the derivative restriction fails if parents and children can use bargaining strategies other than the reaction function that we assume. ${ }^{46}$

Given the large discrepancy between the results and the prediction of the basic altruism model, a satisfactory model of transfers is likely to involve factors in addition to altruism. First, suppose that parents get utility from $\mathrm{R}$ independently of the child's utility. This warm glow motive tends to reduce the difference in derivatives. Second, Cox's theoretical analysis implies that, at least in a static context, the difference in derivatives is less than 1 if transfers are made in exchange for services from the child. Cox (1987), Bernheim, Shleifer and Summers (1985), and Cox and Rank (1992) provide some direct evidence on child services (such as visits and phone calls) that supports a role for exchange. However, in AHK (1992a) we analyze the 1988 PSID data on time-help provided to parents and find that it has little relationship to the parents' income or wealth, in contrast to the predictions of simple exchange models. Also, we find that differences between siblings in the receipt of money transfers depend on the relative incomes of the siblings, but have little to do with the relative amounts of time they spend helping their parents. Finally, we find that while differences in distance from parents have a strong effect on flows of time-help, it has little effect on flows of money-help. In an exchange model, the reduction with distance in time flows should lead to a reduction in money flows.

\section{Conclusion}

This paper uses matched panel data on parents and their adult children and a new econometric methodology to produce consistent estimates of the derivatives of transfers with respect to the parents'

\footnotetext{
${ }^{46}$ Bergstrom et. al. (1986) (theorem 7 and page 47 paragraph 2) consider a model that may be interpreted as a static model in which parents care about their own consumption and the consumption of each of their children, and the children care only about their own consumption. The model seems to imply that, if there is a Nash equilibrium in the transfer amounts that involves a positive transfer $R$ to a particular child $j$ and perhaps other children, then following an exogenous increase in the parents' income of 1 dollar and reduction of $j$ 's income by 1 dollar, transfers of $R+1$ to child $j$ and the original amounts to the other children are a Nash equilibrium. This suggests that the derivative restriction may carry over to some other bargaining models.
} 
income and the child's income. We then use our estimates to test a fundamental prediction of altruistic preferences---the difference in the derivatives should equal 1. The paper's econometric approach may be useful in analyzing other consumer choice problems that involve overlapping budget constraints and limited dependent variables, such as estimating the effects of public transfers on private transfers or charitable giving, testing whether public transfers crowd out private transfers, and analyzing the effects of the endowments of the wife and husband on resource allocation within the household.

We find that parents increase their transfers by a few cents for each extra dollar of current or permanent income they have, which in itself is consistent with altruism. The inconsistency arises because we also find that parents reduce transfers by only a few cents for each extra dollar of income their child has. As we show in Section 2, the difference in the transfer-income derivatives should be 1, while our estimates are concentrated in the .04 to .13 range depending on the choice of income measure and point at which the derivatives are evaluated. Our results our robust to change in functional form, outliers, number of siblings, the definition of current and permanent income, and measurement error in income and wealth. 


\section{References}

Altig, David and Steven J. Davis, "The Timing of Intergenerational Transfers, Tax Policy, and Aggregate Savings," The American Economic Review, vol. 82, no. 5, December 1992, 1199-1220.

Altonji, Joseph G., "Estimating Derivatives in Nonlinear Regression Models with Limited Dependent Variables" mimeo, Northwestern University, May 1993.

Altonji, Joseph G., Fumio Hayashi and Laurence J. Kotlikoff, "Is the Extended Family Altruistically Linked? Direct Evidence Using Micro Data," American Economic Review, vol. 82, no. 5, December 1992a, 1177-1198.

Altonji, Joseph G., Fumio Hayashi and Laurence J. Kotlikoff, "The Effects of Income and Wealth on Time and Money Transfers Between Parents and Children", mimeo, Northwestern University, (October 1992b)

Andreoni, James, "Giving with Impure Altruism: Applications to Charity and Ricardian Equivalence", vol 97 No. 6 (December 1989): 1447-1458.

Barro, Robert J. "Are Government Bonds Net Wealth?", Journal of Political Economy, vol. 82, no. 6, November/December 1974, 1095-1117.

Becker, Gary S., A Treatise on the Family, Cambridge, Mass.: Harvard University Press, 1991.

Becker, Gary S., "A Theory of Social Interactions", Journal of Political Economy, vol. 82, no. 6, November/December 1974, 1063-1093.

Ben Porath, Yoram, "The F-Connection: Families, Friends, and Firms and the Organization of Exchange," Population Development Review, vol. 6, no. 1, March 1980, 1-30.

Bernheim, B. Douglas, Andre Shleifer, and Lawrence H. Summers, "The Strategic Bequest Motive," Journal of Political Economy, vol. 93, no. 6, December 1985, 1045-1076.

Bergstrom Ted (1993) "A Survey of Theories of the Family", unpublished paper, University of Michigan (May 1993).

Blinder, Alan S., "Intergenerational Transfers and Life Cycle Consumption," American Economic Review, vol. 66, no. 2, May 1976, 87-93.

Blundell, Richard and Costas Meghir, "Bivariate Alternatives to the Tobit Model", Journal of Econometrics 34 (1987): 179-200

Cox, Donald, "Motives for Private Income Transfers," Journal of Political Economy, vol. 95, no. 3, June 1987, 508- 546.

Cox, Donald, "Intergenerational Transfers and Liquidity Constraints," Quarterly Journal of Economics, vol. 105, February 1990, 187- 218. 
Cox, Donald and Mark Rank, "Inter-Vivos Transfers and Intergenerational Exchange," Review of Economics and Statistics, vol. 74, no. 2, May 1992, 304-14.

Drazen, Allan, "Government Debt, Human Capital, and Bequests in a Life-Cycle Model," Journal of Political Economy, vol. 86, no. 3, June 1978, 505-516.

Dunn, Thomas A., "The Distribution of Intergenerational Income Transfers Between and Within Families," mimeo, Syracuse University, May 1993

Gale, William G. and John Karl Scholz, "Intergenerational Transfers and the Accumulation of Wealth," The Journal of Economic Perspectives. 8:4 (Fall 1994):145-160.

Hayashi, Fumio, "Is the Extended Family Altruistically Linked? A Test Based on Engel Curves". Journal of Political Economy, 103 No. 3 (June 1995): 661-674.

Hill, Martha and Beth Soldo, "Intergenerational Transfers: Economic, Demographic and Social Perspectives (1993)

Ioannides, Yannis M. and Kamhon Kan, "The Nature of Two-Directional Intergenerational Transfers of Money and Time: An Empirical Analysis," mimeo, Department of Economics, Virginia Polytechnic Institute and State University, March 23, 1993.

Kotlikoff, Laurence J. and Assaf Razin, "Making Bequests Without Spoiling Children," NBER working paper no. 2735, October 1988.

Kotlikoff, Laurence J. and Avia Spivak, "The Family as an Incomplete Annuities Market," Journal of Political Economy, vol. 89, no. 2, April 1981, 372-391.

Kotlikoff, Laurence J. and Robert Rosenthal, "A Strategic Altruism Model in Which Ricardian Equivalence Does Not Hold," The Economic Journal, vol. 100, no. 403, December 1990, pp. 1261-1268.

Menchik, Paul L., "Primogeniture, Equal Sharing, and the U.S. Distribution of Wealth," Quarterly Journal of Economics, vol. 94, no. 2, March 1980, 299-316.

Pollak, Harold, Informal Transfers Within Families. unpublished Ph. D. Distribution, Harvard University (September 1994).

Pollak, Robert A., "A Transactions Cost Approach to Families and Households," Journal of Economic Literature, XXIII, 2, June 1985, 581-663.

Rosenzweig, Mark R. and Kenneth I. Wolpin, "Intergenerational Support and the Life-Cycle Incomes of Young Men and Their Parents: Human Capital Investments, Co-Residence and Interhousehold Transfers," Journal of Labor Economics 111 (1993):84-112

Rosenzweig, Mark R. and Kenneth I. Wolpin, "Parental and Public Transfers to Young Women and Their Children," American Economic Review (1994) 
Schoeni, Robert F. "Private Interhousehold Transfers of Money and Time: New Empirical Evidence", Labor and Population Program Working Paper, RAND Corporation, 93-26 (July 1993)

Thomas, Duncan, "Intra-household Resource Allocation: An Inferential Approach" Journal of Human Resources 25 (Fall 1990): 599-634.

Wilhelm, Mark, "Bequest Behavior and the Effect of Heirs' Income: Testing the Altruistic Model of Bequests," mimeo, Penn State University, 1991. 


\section{Effects of Measurement Error in Tranfers}

Suppose $R^{*}=I$ e $R$, where $I$ is a bernoulli random variable which takes on the value 1 with probability $p_{I}$ and 0 with probability $\left(1-p_{I}\right)$, $e$ is a positive random variable which is independent of $R$ and has a mean of $e^{-}$conditional on $R>0$, and $e$ equals 1 . These assumptions plus (4.6) imply that the expectation of $R^{*}$ conditional on $Y_{p}, Y_{k}$ and $R^{*}>0$ is

(A.1) $\quad \bar{R}^{*}(Z)=\overline{\mathrm{e}} \int_{\eta^{*}(Z)} \mathrm{R}(Z, \eta) \frac{\mathrm{g}(\eta) \mathrm{d} \eta}{\mathrm{P}_{\mathrm{R}}(Z)}$.

They also imply that

$\operatorname{Prob}\left(R^{*}>0 \mid Z\right)=p_{I} P_{R}(Z)=p_{I} \int_{\eta^{*}(Z)} g(\eta) d \eta$

It follows almost immediately from the derivation of $(2.12 \mathrm{~b})$ above that if one uses our procedure above to estimate $\Delta E\left(\frac{\delta R(Z)}{\delta Y_{j t}} \mid Z, R>0\right)$, but uses $R^{*}$ instead of $R$ as the measure of transfers, then one will estimate $\overline{\mathrm{e}} \Delta \mathrm{E}\left(\frac{\delta \mathrm{R}(\mathrm{Z})}{\delta \mathrm{Y}_{\mathrm{jt}}} \mid \mathrm{Z}, \mathrm{R}>0\right)$

Hence, random reporting error in transfers has no effect on our tests if $\bar{e}=1$, even if a fraction of individuals who receive transfers fail to report them. If those who receive transfers tend to understate the size of the gifts, our derivate estimator is biased downward in abolute value and the test will be biased against the altruism hypothesis. 
Table 1: Means by Transfer Category

\begin{tabular}{|c|c|c|c|c|}
\hline Variable & Label & $\begin{array}{l}\text { Total } \\
\text { Sample }\end{array}$ & $\begin{array}{l}\text { If No } \\
\text { Transfer }\end{array}$ & $\begin{array}{l}\text { If } \\
\text { Transfer }\end{array}$ \\
\hline KRMGPKI & parent gave kid money $0 / 1$ & 0.202 & 0.000 & 1.000 \\
\hline KRMGPKA & Amount of money parent gave kid & $\begin{array}{r}297.0 \\
(2064.5)\end{array}$ & $\begin{array}{r}0.000 \\
(0.000)\end{array}$ & $\begin{array}{r}1507.8 \\
(4453.5)\end{array}$ \\
\hline KSINFEM & Kid is unmarried female & 0.230 & 0.228 & 0.240 \\
\hline KSINMAL & Kid is unmarried male & 0.167 & 0.148 & 0.245 \\
\hline KMARFEM & Kid is married female & 0.304 & 0.316 & 0.256 \\
\hline KNKID88 & Number of children in kid household & 1.237 & 1.318 & 0.917 \\
\hline KSINKIDS & $\begin{array}{l}\text { Number of children in single kid } \\
\text { household }\end{array}$ & 0.295 & 0.307 & 0.245 \\
\hline FATHDSIN & Parent is divorced unmarried father & 0.023 & 0.024 & 0.019 \\
\hline FATHDREM & Parent is divorced remarried father & 0.043 & 0.044 & 0.038 \\
\hline FATHWSIN & Parent is widowed unmarried father & 0.026 & 0.028 & 0.016 \\
\hline FATHWREM & Parent is widowed remarried father & 0.017 & 0.019 & 0.012 \\
\hline MOTHDSIN & Parent is divorced unmarried mother & 0.093 & 0.094 & 0.086 \\
\hline MOTHDREM & Parent is divorced remarried mother & 0.050 & 0.050 & 0.049 \\
\hline MOTHWSIN & Parent is widowed unmarried mother & 0.184 & 0.194 & 0.144 \\
\hline MOTHWREM & Parent is widowed remarried mother & 0.032 & 0.035 & 0.022 \\
\hline KRPLVAPT & Parent's married but live apart & 0.021 & 0.023 & 0.010 \\
\hline NONWHITE & Kid reports race other than white & 0.357 & 0.385 & 0.246 \\
\hline KAGE & Age of kid & $\begin{array}{r}30.527 \\
(5.802)\end{array}$ & $\begin{array}{r}30.891 \\
(5.786)\end{array}$ & $\begin{array}{l}29.087 \\
(5.642)\end{array}$ \\
\hline PAGE & Age of parent & $\begin{array}{r}58.719 \\
(8.349)\end{array}$ & $\begin{array}{r}58.965 \\
(8.257)\end{array}$ & $\begin{array}{r}57.745 \\
(8.642)\end{array}$ \\
\hline KHLTH88 & Health of kid in $88,1=$ excel. $5=$ poor & $\begin{array}{r}2.096 \\
(0.947)\end{array}$ & $\begin{array}{r}2.117 \\
(0.956)\end{array}$ & $\begin{array}{r}2.016 \\
(0.907)\end{array}$ \\
\hline PHLTH88 & Health of parent in $88,1=$ excel. $5=$ poor & $\begin{array}{r}3.115 \\
(1.173)\end{array}$ & $\begin{array}{r}3.171 \\
(1.176)\end{array}$ & $\begin{array}{l}2.894 \\
(1.135)\end{array}$ \\
\hline KRPDIST & Distance to parent house-estimated & $\begin{array}{r}141.454 \\
(210.737)\end{array}$ & $\begin{array}{r}139.432 \\
(209.739)\end{array}$ & $\begin{array}{r}149.447 \\
(214.604)\end{array}$ \\
\hline PINHOUS & Parent resides with kid & 0.069 & 0.063 & 0.093 \\
\hline PINORH & Parent lives with another relative & 0.018 & 0.020 & 0.013 \\
\hline INVNKID & Inverse of number of kids & $\begin{array}{r}0.273 \\
(0.181)\end{array}$ & $\begin{array}{r}0.260 \\
(0.173)\end{array}$ & $\begin{array}{r}0.321 \\
(0.201)\end{array}$ \\
\hline$Y_{p}$ & $\begin{array}{l}\text { Parent's permanent income-time } \\
\text { averaged method }\end{array}$ & $\begin{array}{r}54.746 \\
(30.821)\end{array}$ & $\begin{array}{r}51.481 \\
(27.510)\end{array}$ & $\begin{array}{r}67.649 \\
(38.814)\end{array}$ \\
\hline$Y_{k}$ & $\begin{array}{l}\text { Kid's permanent income-time averaged } \\
\text { method }\end{array}$ & $\begin{array}{r}48.171 \\
(24.286)\end{array}$ & $\begin{array}{r}47.644 \\
(23.868)\end{array}$ & $\begin{array}{r}50.254 \\
(25.785)\end{array}$ \\
\hline $\mathrm{Y}_{\mathrm{p}}$ & $\begin{array}{l}\text { Parent's permanent income- } \\
\text { autoregressive method }\end{array}$ & $\begin{array}{r}53.403 \\
(23.682)\end{array}$ & $\begin{array}{r}50.976 \\
(21.350)\end{array}$ & $\begin{array}{r}62.996 \\
(29.355)\end{array}$ \\
\hline$\hat{\mathrm{Y}}_{\mathrm{k}}$ & $\begin{array}{l}\text { Kid's permanent income-autoregressive } \\
\text { method }\end{array}$ & $\begin{array}{r}46.207 \\
(14.942)\end{array}$ & $\begin{array}{r}45.949 \\
(14.869)\end{array}$ & $\begin{array}{r}47.223 \\
(15.195)\end{array}$ \\
\hline $\mathrm{N}$ & Number of observations & 3402 & 2715 & 687 \\
\hline
\end{tabular}

Note: Standard deviations in parentheses. Sample is unweighted. 
TABLE 2

Distribution of Positive Transfers

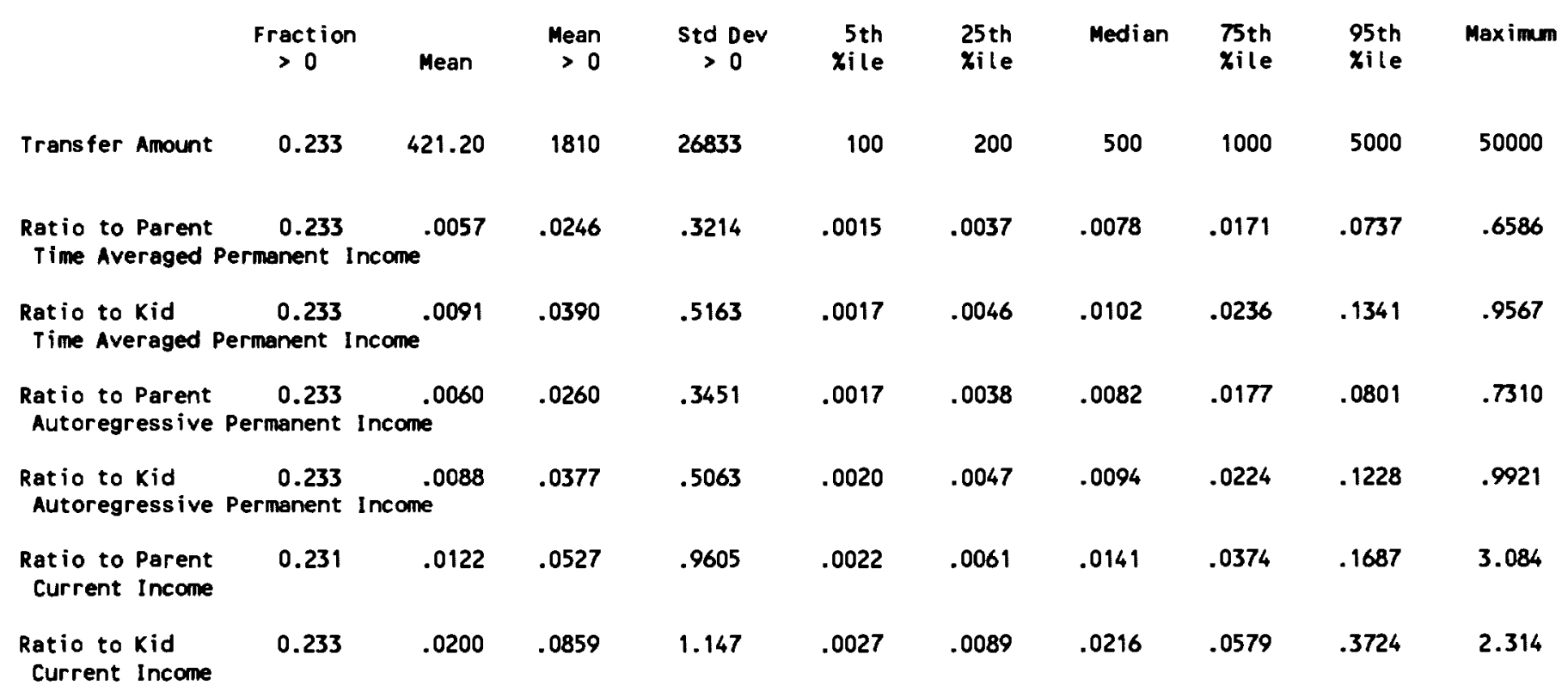

Note: Sample sizes vary slightly due to missing values. Weighted estimates. Transfers from perents living in separate households are combined 


\section{TABLE 3}

PROBABILITY OF MONEY TRANSFER TO KID AMO MEAN TRANSFER AMOUNT

BY PERMANENT INCOME OF PARENT AMD KID

\begin{tabular}{|c|c|c|c|c|c|c|c|c|c|c|c|c|}
\hline \multirow{2}{*}{\multicolumn{2}{|c|}{$\mid$}} & \multicolumn{2}{|c|}{$\begin{array}{c}1 \text { owest } / \text { second } \\
(18,456)\end{array}$} & $\left|\begin{array}{c}\text { permaner } \\
(35,936)\end{array}\right|$ & $\begin{array}{l}\text { nt income } \\
\left(\begin{array}{c}\text { fourth } \\
(42,193)\end{array}\right.\end{array}$ & $\begin{array}{c}\text { decile of } \\
\left|\begin{array}{c}\text { fifth } \\
(47,266)\end{array}\right|\end{array}$ & $\begin{array}{l}\text { f child }(a \\
\left|\begin{array}{c}\text { sixth } \\
(52,218)\end{array}\right|\end{array}$ & $\begin{array}{l}\text { avg. incon } \\
\left|\begin{array}{l}\text { seventh } \\
(58,373)\end{array}\right|\end{array}$ & $\begin{array}{l}\text { me) } \\
\cdots \\
\text { eighth } \\
(65,851)\end{array} \mid$ & $\left|\begin{array}{c}\text { ninth } \\
(76,302)\end{array}\right|$ & $\mid \begin{array}{l}\text { highest } \\
(103,508)\end{array}$ & \multirow[t]{2}{*}{$\begin{array}{c}\text { total } \\
(52,926)\end{array}$} \\
\hline & & & & & & & & & & & & \\
\hline $\begin{array}{l}\text { lowest } \\
(22,764)\end{array}$ & $\mid \begin{array}{l}\text { probability } \\
\text { mean } \\
\text { sample size }\end{array}$ & $\begin{array}{r}0.110 \\
432 \\
219\end{array}$ & $\begin{array}{r}0.181 \\
568 \\
93\end{array}$ & $\begin{array}{r}0.103 \\
297 \\
76\end{array}$ & $\begin{array}{r}0.055 \\
260 \\
71\end{array}$ & $\begin{array}{r}0.056 \\
962 \\
47\end{array}$ & $\begin{array}{r}0.126 \\
324 \\
39\end{array}$ & $\begin{array}{r}0.097 \\
321 \\
26\end{array}$ & $\begin{array}{r}0.261 \\
411 \\
21\end{array}$ & $\begin{array}{r}0.018 \\
300 \\
17\end{array}$ & $\begin{array}{r}0.036 \\
100 \\
12\end{array}$ & $\begin{array}{r}0.111 \\
452 \\
621\end{array}$ \\
\hline $\begin{array}{l}\text { second } \\
(32,686)\end{array}$ & $\begin{array}{l}\text { probability } \\
\text { mean } \\
\text { sample size }\end{array}$ & $\begin{array}{r}0.162 \\
392 \\
116\end{array}$ & $\begin{array}{r}0.176 \\
570 \\
82\end{array}$ & $\begin{array}{r}0.104 \\
271 \\
72\end{array}$ & $\begin{array}{r}0.104 \\
284 \\
41\end{array}$ & $\begin{array}{r}0.046 \\
100 \\
34\end{array}$ & $\begin{array}{r}0.226 \\
1434 \\
36\end{array}$ & $\begin{array}{r}0.066 \\
142 \\
30\end{array}$ & $\begin{array}{r}0.089 \\
971 \\
30\end{array}$ & $\begin{array}{r}0.308 \\
806 \\
23\end{array}$ & $\begin{array}{r}0.000 \\
i\end{array}$ & $\begin{array}{r}0.140 \\
645 \\
468\end{array}$ \\
\hline $\begin{array}{l}\text { third } \\
(39,556)\end{array}$ & $\begin{array}{l}\text { probabil ity } \\
\text { mean } \\
\text { sample size }\end{array}$ & $\begin{array}{r}0.302 \\
1210 \\
84\end{array} \mid$ & $\begin{array}{r}0.264 \\
338 \\
44\end{array}$ & $\begin{array}{r}0.132 \\
437 \\
47\end{array}$ & $\begin{array}{r}0.198 \\
784 \\
51\end{array}$ & $\begin{array}{r}0.136 \\
5484 \\
47\end{array}$ & $\begin{array}{r}0.137 \\
325 \\
38\end{array}$ & $\begin{array}{r}0.094 \\
4590 \\
31\end{array}$ & $\begin{array}{r}0.266 \\
5061 \\
33\end{array}$ & $\begin{array}{r}0.239 \\
703 \\
25\end{array}$ & $\begin{array}{r}0.213 \\
699 \\
18\end{array}$ & $\begin{array}{r}0.190 \\
1986 \\
418\end{array}$ \\
\hline $\begin{array}{l}\text { four th } \\
(45,907)\end{array}$ & $\mid \begin{array}{l}\text { probability } \\
\text { mean } \\
\text { sample size }\end{array}$ & $\begin{array}{r}0.318 \\
739 \\
51\end{array}$ & $\begin{array}{r}0.182 \\
370 \\
45\end{array}$ & $\begin{array}{r}0.173 \\
1468 \\
43\end{array}$ & $\begin{array}{r}0.358 \\
2464 \\
39\end{array}$ & $\begin{array}{r}0.140 \\
323 \\
30\end{array}$ & $\begin{array}{r}0.074 \\
543 \\
29\end{array}$ & $\begin{array}{r}0.178 \\
114 \\
32\end{array}$ & $\begin{array}{r}0.174 \\
553 \\
22\end{array}$ & $\begin{array}{r}0.089 \\
500 \\
20\end{array}$ & $\begin{array}{r}0.157 \\
146 \\
15\end{array}$ & $\begin{array}{r}0.197 \\
1007 \\
326\end{array}$ \\
\hline $\begin{array}{l}\text { fifth } \\
(51,922)\end{array}$ & $\begin{array}{l}\text { probabi l i ty } \\
\text { mean } \\
\text { sample size }\end{array}$ & $\begin{array}{r}0.416 \\
469 \\
52\end{array}$ & $\begin{array}{r}0.154 \\
1303 \\
50\end{array}$ & $\begin{array}{r}0.230 \\
1722 \\
40\end{array}$ & $\begin{array}{r}0.173 \\
876 \\
35\end{array}$ & $\begin{array}{r}0.3 \pi \\
6131 \\
30\end{array}$ & $\begin{array}{r}0.258 \\
484 \\
38\end{array}$ & $\begin{array}{r}0.315 \\
376 \\
24\end{array}$ & $\begin{array}{r}0.177 \\
413 \\
25\end{array}$ & $\begin{array}{r}0.188 \\
705 \\
29\end{array}$ & $\begin{array}{r}0.152 \\
1456 \\
21\end{array}$ & $\begin{array}{r}0.228 \\
1549 \\
344\end{array}$ \\
\hline $\begin{array}{l}\text { sixth } \\
(58,112)\end{array}$ & $\begin{array}{l}\text { probabi l ity } \\
\text { mean } \\
\text { sample size }\end{array}$ & $\begin{array}{r}0.259 \\
255 \\
33\end{array}$ & $\begin{array}{r}0.375 \\
551 \\
32\end{array}$ & $\begin{array}{r}0.357 \\
1676 \\
28\end{array}$ & $\begin{array}{r}0.320 \\
689 \\
24\end{array}$ & $\begin{array}{r}0.123 \\
484 \\
30\end{array}$ & $\begin{array}{r}0.226 \\
788 \\
35\end{array}$ & $\begin{array}{r}0.213 \\
2243 \\
34\end{array} \mid$ & $\begin{array}{r}0.241 \\
1209 \\
34\end{array}$ & $\begin{array}{r}0.208 \\
3856 \\
25\end{array}$ & $\begin{array}{r}0.205 \\
850 \\
27\end{array}$ & $\begin{array}{r}0.240 \\
1285 \\
302\end{array}$ \\
\hline $\begin{array}{l}\text { seventh } \\
(65,081)\end{array}$ & $\begin{array}{l}\text { probabil ity } \\
\text { mean } \\
\text { sample size }\end{array}$ & $\begin{array}{r}0.374 \\
415 \\
15\end{array}$ & $\begin{array}{r}0.256 \\
1430 \\
26\end{array}$ & $\begin{array}{r}0.348 \\
485 \\
30\end{array}$ & $\begin{array}{r}0.447 \\
1040 \\
33\end{array}$ & $\begin{array}{r}0.271 \\
604 \\
27\end{array}$ & $\begin{array}{r}0.146 \\
676 \\
33\end{array}$ & $\begin{array}{r}0.274 \\
703 \\
37\end{array}$ & $\begin{array}{r}0.200 \\
395 \\
33\end{array}$ & $\begin{array}{r}0.372 \\
690 \\
30\end{array}$ & $\begin{array}{r}0.336 \\
649 \\
29\end{array}$ & $\begin{array}{r}0.297 \\
718 \\
293\end{array}$ \\
\hline $\begin{array}{l}\text { eighth } \\
(74,284)\end{array}$ & $\begin{array}{l}\text { probabi l ity } \\
\text { mean } \\
\text { sample size }\end{array}$ & $\begin{array}{r}0.680 \\
828 \\
17\end{array}$ & $\begin{array}{r}0.601 \\
1767 \\
22\end{array}$ & $\begin{array}{r}0.217 \\
614 \\
23\end{array}$ & $\begin{array}{r}0.267 \\
2356 \\
27\end{array}$ & $\begin{array}{r}0.444 \\
2528 \\
23\end{array}$ & $\begin{array}{r}0.291 \\
10638 \\
20\end{array}$ & $\begin{array}{r}0.300 \\
1804 \\
21\end{array}$ & $\begin{array}{r}0.242 \\
978 \\
32\end{array}$ & $\begin{array}{r}0.180 \\
613 \\
36\end{array}$ & $\begin{array}{r}0.223 \\
1048 \\
34\end{array}$ & $\begin{array}{r}0.306 \\
2242 \\
255\end{array}$ \\
\hline $\begin{array}{l}\text { inth } \\
(86,699)\end{array}$ & $\mid \begin{array}{l}\text { probabil ity } \\
\text { mean } \\
\text { sample size }\end{array}$ & $\begin{array}{r}0.597 \\
2226 \\
13\end{array}$ & $\begin{array}{r}0.597 \\
1996 \\
20\end{array}$ & $\begin{array}{r}0.258 \\
1997 \\
12\end{array}$ & $\begin{array}{r}0.227 \\
2619 \\
19\end{array}$ & $\begin{array}{r}0.368 \\
8031 \\
20\end{array}$ & $\begin{array}{r}0.312 \\
2326 \\
23\end{array}$ & $\begin{array}{r}0.181 \\
4207 \\
31\end{array}$ & $\begin{array}{r}0.372 \\
688 \\
29\end{array}$ & $\begin{array}{r}0.298 \\
704 \\
31\end{array}$ & $\begin{array}{r}0.382 \\
3274 \\
36\end{array}$ & $\begin{array}{r}0.346 \\
2767 \\
234\end{array}$ \\
\hline $\begin{array}{l}\text { highest } \\
(127,674)\end{array}$ & $\mid \begin{array}{l}\text { probabi i i ty } \\
\text { mean } \\
\text { sample size }\end{array}$ & $\begin{array}{r}0.187 \\
14034 \\
17\end{array}$ & $\begin{array}{r}0.503 \\
414 \\
13\end{array}$ & $\begin{array}{r}0.366 \\
2001 \\
23\end{array}$ & $\begin{array}{r}0.565 \\
2277 \\
22\end{array}$ & $\begin{array}{r}0.614 \\
3104 \\
24\end{array}$ & $\begin{array}{r}0.110 \\
3867 \\
30\end{array}$ & $\begin{array}{r}0.292 \\
1524 \\
34\end{array}$ & $\begin{array}{r}0.276 \\
2251 \\
26\end{array}$ & $\begin{array}{r}0.253 \\
5254 \\
52\end{array}$ & $\begin{array}{r}0.412 \\
3435 \\
59\end{array}$ & $\begin{array}{r}0.344 \\
3206 \\
300\end{array}$ \\
\hline $\begin{array}{l}\text { total } \\
(62,584)\end{array}$ & $\begin{array}{l}\text { probability } \\
\text { mean } \\
\text { sample size }\end{array}$ & $\begin{array}{r}0.261 \\
1295 \\
617\end{array}$ & $\begin{array}{r}0.275 \\
1055 \\
427\end{array}$ & $\begin{array}{r}0.207 \\
1159 \\
394\end{array}$ & $\begin{array}{r}0.275 \\
1600 \\
362\end{array}$ & $\begin{array}{r}0.249 \\
3499 \\
312\end{array}$ & $\begin{array}{r}0.191 \\
2507 \\
321\end{array} \mid$ & $\begin{array}{r}0.217 \\
1569 \\
300\end{array}$ & $\begin{array}{r}0.232 \\
1392 \\
285\end{array}$ & $\begin{array}{r}0.241 \\
2066 \\
288\end{array}$ & $\begin{array}{r}0.297 \\
2350 \\
255\end{array}$ & $\begin{array}{r}0.244 \\
1851 \\
3561\end{array}$ \\
\hline
\end{tabular}


Table $3 a$

PROBABILITY OF MONEY TRANSFER TO KID AND MEAN TRANSFER AMOUNT

BY CURRENT INCOME OF PARENT AND CURRENT INCOME OF KID 11

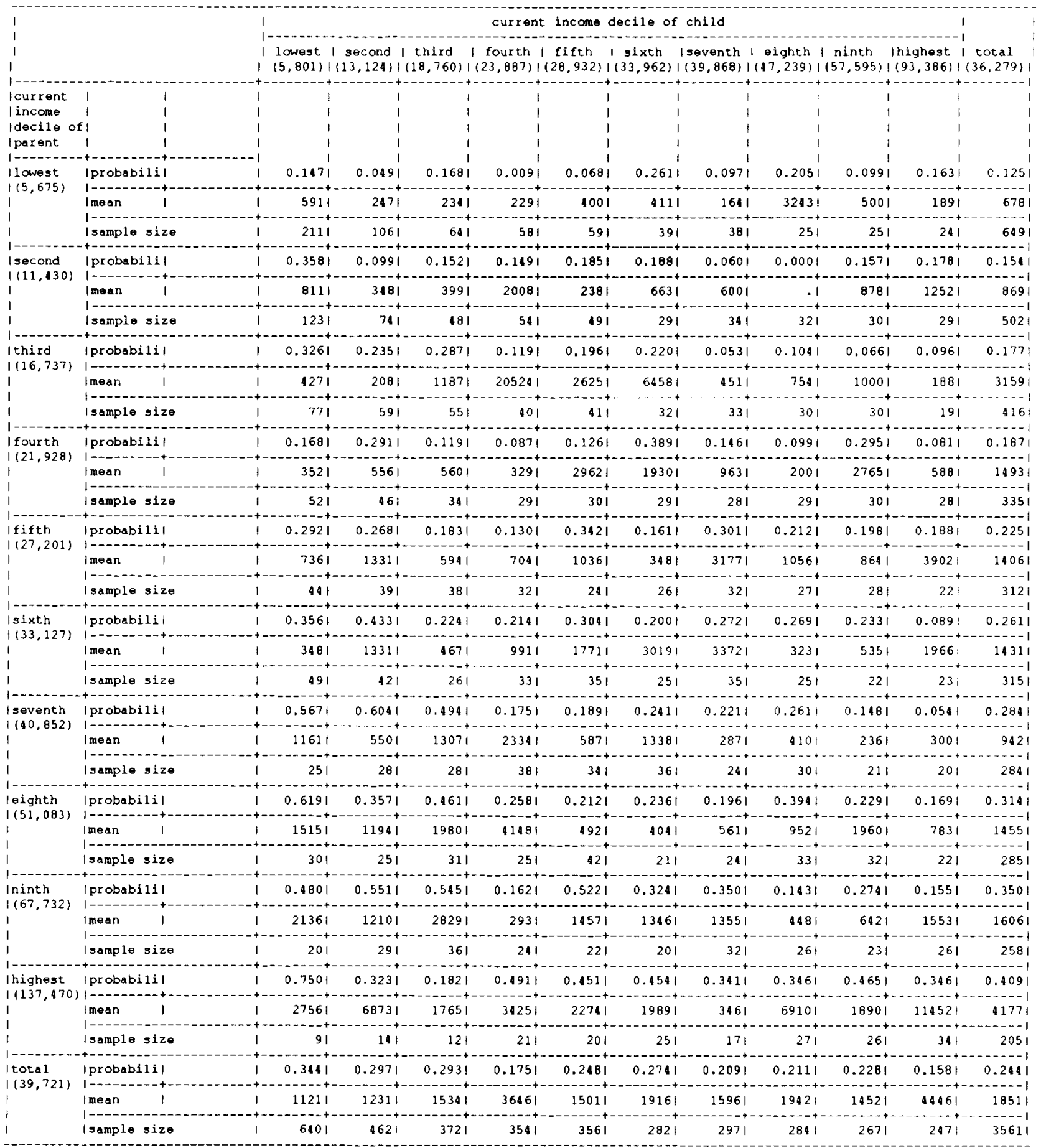

Note:

1) The current income measure is family income. Transfers from parents living in separate households are combined. Estimates are weighted using the 1988 person weights of the children.

\section{AKTBL3D.DOC, 08/05/94 4:59 PM}


TABLE 4

Effects of Income and Weal th on the Probability of a Transfer: Probit Estimates ${ }^{3}$ (Standard errors in parentheses) ${ }^{1}$

\begin{tabular}{|c|c|c|c|c|c|}
\hline $\begin{array}{l}\text { Current Income } \\
\text { Permanent } \\
\text { Income Measure } 2 . \\
\text { Assets }\end{array}$ & $\begin{array}{l}\text { excluded } \\
\bar{Y}_{k}, \bar{Y}_{p}(t \text { ine } \\
\text { averaged), } \\
\text { excluded } \\
\text { (1) }\end{array}$ & $\begin{array}{l}\text { non asset income } \\
\bar{y}_{k}, \bar{y}_{p}(t \text { ime } \\
\text { averaged) } \\
\text { yes } \quad \text { (2) }\end{array}$ & $\begin{array}{l}\text { non asset } \\
\text { income } \\
\hat{\gamma}_{k}, \hat{\gamma}_{p}(t \text { ime } \\
\text { averaged) } \\
\text { yes } \quad \text { (3) }\end{array}$ & $\begin{array}{l}\text { earnings } \\
\text { time averaged } \\
\text { earnings } \\
\text { yes (4) }\end{array}$ & $\begin{array}{l}\text { excluded } \\
\text { time averaged } \\
\text { earnings } \\
\text { yes (5) }\end{array}$ \\
\hline
\end{tabular}

Effects of Kid's Current Income:

\begin{tabular}{|c|c|}
\hline $\begin{array}{l}\text { Probit Coefficient, } \\
\text { Linear Specification } \\
\text { standard Error }\end{array}$ & $(1$ \\
\hline Mean of Derivatives & $(2$ \\
\hline $\begin{array}{l}\text { Probability of Transfer } \\
\text { at Median } \\
\text { at 20th percentile } \\
\text { at } 80 \text { th percentile }\end{array}$ & \\
\hline
\end{tabular}

Effects of Parents' Current Income:

(5)

Probit Coefficient,

Linear Specification

Standard Error

(6)

Mean of Derivatives

(7)

Probability of Transfer

at Median

at 20th percentile

at 80th percentile

Effects of Kid's Permanent Income:

Probit Coefficient,

Standard Error

(11)

$-.0038$

(.0012)

Mean of Derivatives

$-.0013$

Probability of Transfer at Median

at 20th percentile at 80th percentile

(14)

(15)

Effects of Parents' Permanent Income:

Probit Coefficient,

Linear Specification

standard Error

(16)

.0105

(.0010)

Mean of Derivatives

(17)

.0036

Probability of Transfer at Median

at 20 th percentile

at 80 th percentile
(19) $\quad .170$

(20) $\quad .262$
$-.0044$

(.0021)

$-.0021$

.145

.176

.116
. .0039

(.0021)

$-.0020$

.145

.176
.117
$-.0037$

(.0022)

$-.0020$

.137

.165

.116
.0036

(.0011)

.0014

.145

.127

.183

$-.0021$

(.0016)

$-.0003$

.145

.152

.139
$-.0042$

(.0028)

$-.0006$

.145

.149

.136
$-.0106$

(.0050)

$-.0027$

$(.0013)$

$-.0015$

.137

.150

.120
.154

.181

.133
.0075

(.0013)

.0024

.145

.096

.197
.0092

(.0017)

.0028

.145
100

.192
.0088

(.0023)

.0039

.0061

(.0010)

.0025

.137

.101

.203
.154

.100

.215 
Effects of Kid's Weal th:

Probit Coefficient. Linear Specification Standard Error

Mean of Derivatives

Probability of Transfer at Median

at 20 th percentile

at 80 th percentile
(21)

Effects of Parents' Wealth:

Probit Coefficient, Linear Specification standard Error

Mean of Derivatives

Probability of Transfer at Median at 20th percentile at 80th percentile
(2)

(3)

(4)

(5)

.00001

(.00069)

.00005

.145

.145

.146

.145

.144

.146

.137

.136

.140

.155

.149

Notes:

1. Conventional asymtotic standard errors for the Probit estiamtor. They do not correct for correlation across observations involving siblings or mothers and fathers who are in separate households.

2. The methods used to consturct the "time averaged" and "autoregressive Permanent income measures are described in Section 5 .

3. Other variables in the models include: ksinfem, ksinmal, kmarfem, knkid88, ksinkids, fathdsin, fathdrem, fathwsin, fathwrem, mothdsin, mothdrem, mothwsin, mothwrem, krplvapt, nonwhite, pinhous, pinorh, khlth88, phlth88, krpdist, invnkid, and a cubic in kage and page. See Table 1 for definitions.

4. Column (1) contains 3,402 observations and 687 positive transfer cases. Colums (2) and (3) contain 3062 observations and 618 positive transfer cases. Colum (4) contains 2,850 observations and 601 positive transfers. 4. Probit coefficients and standard errors for the "linear specification" come from models which contain only linear income (and weal th and current income) terms (Rows 1, 6, 11, 16, 21, and 26). All other results are based on models which include a cubic in the income (and wealth) measures and an interaction between the level income terms. Health is measured in thousands of dollars.

5. Probabilities are evaluated at the mean of the included variables and the median of the income and wealth variables. 
TABLE 5

The Effects of Income and Wealth on Transfer Amounts: Tobit Estimates (standard errors in parentheses) ${ }^{1}$

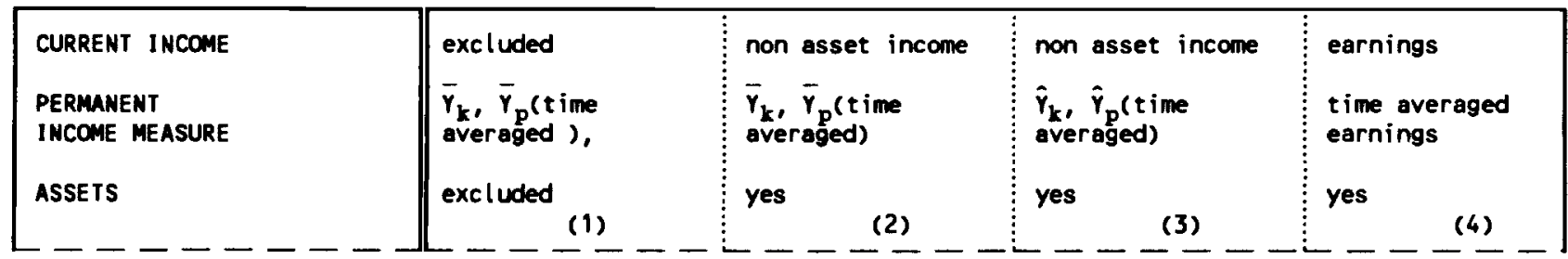

Effects of kid's current income:

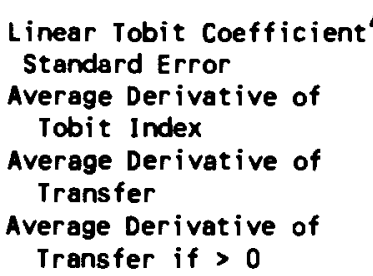

(1)

Effects of parents' current income:

Linear Tobit Coefficient ${ }^{4}$

Standard Error

(5)

Average Derivative of Tobit Index

Average Derivative of Transfer

Average Derivative of Transfer if > 0
$-.023$

(.011)

$-.0716$

$-.0113$

$-.0140$

.009

(.003)

.0243

.0037

.0047

. .010

(.008)

.0091

.0017

.0019

.046

(.006)

.0538

.0071

.0615

.0082

.058

(.008)

047
-.022
$(.011)$

$-.022$

(.011)

.0677

$-.055$

$-.0088$

$-.0108$

Average Derivative of verage Derivative of Transfer

Average Derivative of Transfer if >0

(14) $\quad .07865$

(15) .01051

(16) .01447

$\begin{array}{ll}\text { (9) } & -.018 \\ & (.006) \\ (10) & -.0208 \\ & \\ (11) & -.0032 \\ (12) & -.00400 \\ \text { income: } & \\ \text { (13) } & .0557 \\ & (.0047)\end{array}$

\author{
(1)
}


TABLE 5 (continued)

(1)
(17)

Linear Tobit Coefficient Standard Error

Average Derivative of Probit Index

Average Derivative of Transfer

Average Derivative of Trensfer if > 0

Linear Tobit Coefficient Standard Error

Average Derivative of Tobit Index

Average Derivative of Iransfer

Average Derivative of Transfer if >0
(2)

(3)
3.11
3.24
(3.16)
4.01
(3.17)
17.79
16.42
17.54

2.94

2.83

2.90

3.49

3.54

3.76

1.31

1.31

(1.00)

3.21

(.99)

14.83

19.76

14.28

2.04

2.89

1.97

2.75

3.34

Notes:

1. Conventional tobit asymptotic standard errors in parentheses. They do not correct for correlations anong observations involving separate parent households and the same child or anong siblings.

2. Other variables in the models include: ksinfem, ksimmal, kmarfem, knkids8, ksinkids, fathdsin, fathdrem, fathwsin, fathwrem, mothdsin, mothdrem, mothwsin, mothurem, krplvept, nonwhite, pinhous, pinorh, khl th88, phlth88, krpdist, invnkid, and a cubic in kage and page. See Table 1 for definitions.

3. Colum (1) contains 3,381 observations and 666 positive transfer cases. 21 of the 687 cases with positive transfers used in Table 4 column 1 were excluded because for lack of data on the size of the transfer. Colums (2) and (3) contain 3044 observations and 600 positive transfer cases. Colum (4) contains 2,832 observations and 583 positive transfers.

4. Tobit coefficients and standard errors for the "linear specification" come from models which contain only linear income (and wealth and current income) terms (Rows 1, 5, 9, 13, 17, and 21). All other results are based on models which include a cubic in the income (and wealth) measures and an interaction between the level income terms. Wealth is measured in thousands of dollars.

5. Probabilities are evaluated at the mean of the included variables and the median of the income and wealth variables.

6. Derivatives for income or earnings are the change in transfer for a $\$ 1$ change in income or earnings. Wealth derivatives represent the change in transfer for a $\$ 1000$ change in assets. 
TABLE 6

Effects of the Parents' and Child's Current Income on Transfers

Derivative Estimator for Nonlinear Limited Dependent Variables Models (Bootstrapped Standard Errors in Parentheses)

Evaluation Point

\section{Parents' Income $\left(\mathrm{Y}_{\mathrm{pt}}\right)$ \\ Uncorrected}

Derivative $^{a}$

(1)
Corrected
Derivative $^{b}$

(2) $\frac{\text { Child's Income }\left(\mathrm{Y}_{\mathrm{kt}}\right)}{\text { Uncorrected } \quad \text { Corrected }}$

Derivative $^{a}$

(3)

$\mathrm{E} \Delta \delta \mathrm{R} / \boldsymbol{\delta} \mathrm{Y}_{\mathbf{j t}}$

Difference in

Derivatives $^{c}$

(5)

Panel A: Time Averaged Measure of Permanent Income: ${ }^{e} \overline{\mathrm{Y}}_{\mathbf{k}}, \overline{\mathrm{Y}}_{\mathrm{p}}$

\begin{tabular}{|c|c|c|c|c|c|c|}
\hline Average of derivatives & (1a) & $\begin{array}{c}.014 \\
(.014)\end{array}$ & $\begin{array}{l}.023 \\
(.077)\end{array}$ & $\begin{array}{l}-.052 \\
(.047)\end{array}$ & $\begin{array}{l}-.066 \\
(.091)\end{array}$ & $\begin{array}{l}.089 \\
(.141)\end{array}$ \\
\hline Sample means & (2a) & $\begin{array}{c}.009 \\
(.011)\end{array}$ & $\begin{array}{l}.035 \\
(.015)\end{array}$ & $\begin{array}{l}-.048 \\
(.026)\end{array}$ & $\begin{array}{l}-.088 \\
(.036)\end{array}$ & $\begin{array}{l}.123 \\
(.037)\end{array}$ \\
\hline $\begin{array}{l}\text { Sample means } \\
\mathrm{Y}_{\mathrm{pt}}=80 \%, \mathrm{Y}_{\mathrm{kt}}=20 \%\end{array}$ & (3a) & $\begin{array}{l}.006 \\
(.016)\end{array}$ & $\begin{array}{c}.038 \\
(.018)\end{array}$ & $\begin{array}{l}-.055 \\
(.060)\end{array}$ & $\begin{array}{l}-.126 \\
(.079)\end{array}$ & $\begin{array}{l}.164 \\
(.096)\end{array}$ \\
\hline $\begin{array}{l}\text { Sample means } \\
\mathrm{Y}_{\mathrm{pt}}=20 \%, \mathrm{Y}_{\mathrm{kt}}=80 \%\end{array}$ & $(4 a)$ & $\begin{array}{c}.020 \\
(.019)\end{array}$ & $\begin{array}{r}.035 \\
(.023)\end{array}$ & $\begin{array}{l}-.057 \\
(.028)\end{array}$ & $\begin{array}{c}-.090 \\
(.033)\end{array}$ & $\begin{array}{l}.125 \\
(.040)\end{array}$ \\
\hline
\end{tabular}

Panel B: Autoregressive Measure of Permanent Income ${ }^{e} \widehat{Y}_{k}, \hat{Y}_{p}$

Average of derivatives

(1b) $\begin{array}{r}.016 \\ (.014)\end{array}$

(2b) $\begin{gathered}.010 \\ (.011)\end{gathered}$

$(2 \mathrm{c})$

Sample means

$\mathrm{Y}_{\mathrm{pt}}=80 \%, \mathrm{Y}_{\mathrm{kt}}=20 \%$

Sample means

$\mathrm{Y}_{\mathrm{pt}}=20 \%, \mathrm{Y}_{\mathrm{kt}}=80 \%$

(2d) $\begin{gathered}.021 \\ (.019)\end{gathered}$

.026
$(.070)$

.031
$(.014)$

.028

$(.018)$

$(.043$

-.054
$(.035)$

$-.067$

(.120)

.093

${ }^{a} \delta \bar{R}(Z) / \delta Y_{j t} ; j=p$ in column (1) and $k$ in column (3).

$-.050$

$-.079$

(.034)

$(.035)$

$-.059$

$(.058)$

$-.104$

(.077)

.132

-.058
$(.028)$

$-.072$

(.031)

115

(.040)

$b\left[\delta \bar{R}(Z) / \delta Y_{j t}\right]+\frac{\bar{R}(Z) \delta P_{R}(Z) / \delta Y_{j t}}{P_{R}(Z)} ; j=p$ in column 1 and $k$ in column (2).

${ }^{c}$ Column (2)-column (4).

See Section 4 for a description of the estimation procedure and the bootstrap method used to compute the standard errors. The sample used to estimate equation (4.13) contains 666 observations. The sample used to estimate (4.14) contains 3402 observations. Equations also control for permanent income of the parent, permanent income of the child, assets of the parent in 1984 and assets of the child in 1984, separate dummy variables for whether assets of the parent in 1984 are missing, assets of the child in 1984 are missing, or assets of either the parent or the child are missing, and the controls listed in Table 4, note 1 .

e Permanent income is calculated using the time averaged method in Panel A and the autoregressive method in Panel B. See Section 5. 
TABLE 7: Effects of the Parents' and Child's Permanent Income on Transfers

Derivative Estimator for NonLinear Limited Dependent Variables Models (Bootstrapped Standard Errors in Parentheses)

Parents' Income $\left(Y_{p}\right)$

Uncorrected

Derivative $^{a}$

(1)
Corrected

Derivative $^{b}$
Child's Income $\left(\mathrm{Y}_{\mathrm{k}}\right)$

Uncorrected Derivative $^{a}$

(3)
Corrected

Derivative $^{b}$

(4)
$E \Delta 8 R / 8 Y_{j}$

Difference in Derivatives $^{c}$

(5)

A: Time-Averaged Measure of Permanent Income : $\bar{Y}_{k}, \bar{Y}_{p}$

Evalution Point

(la) Average of derivatives .026

(.008)

$$
.044
$$

.013

(.012)

.037

(.014)

$-.008$

(.023)

.006

(.025)

$\mathrm{Y}_{\mathrm{p}}=80 \%, \mathrm{Y}_{\mathrm{k}}=20 \%$

.049

(.021)
.059

(.022)
$Y_{p}=20 \%, Y_{k}=80 \%$
$-.002$

(.006)

$-.010$

(.006)

.053

$-.008$

$-.017$

.011

(.046)

(.025) (.027)

$-.030$

.089

$-.021$

(.013)

(.013)

B: Autoregressive Measure of Permanent Income: $\widehat{Y}_{k}, \widehat{Y}_{p}$

Evalution Point

(lb) Average of derivatives .031

(.010)

$$
.054
$$

$(.011)$

(2b) Sample means

$$
\begin{gathered}
.018 \\
(.012)
\end{gathered}
$$

.050

(.017)

(3b) Sample means

$\mathrm{Y}_{\mathrm{p}}=80 \%, \mathrm{Y}_{\mathrm{k}}=20 \%$

-.000
$(.026)$

.018
$(.030)$

.068

(.029)

(4b) Sample means

$\mathrm{Y}_{\mathrm{p}}=20 \%, \mathrm{Y}_{\mathrm{k}}=80 \%$

${ }^{a} \delta \overrightarrow{\mathrm{R}}(\mathrm{Z}) / \delta \mathrm{Y}_{\mathrm{j}} ; \mathrm{j}=\mathrm{p}$ in column (1) and $\mathrm{k}$ in column (3).

$b\left[\delta \bar{R}(\mathrm{Z}) / \delta \mathrm{Y}_{\mathrm{j}}\right]+\frac{\overline{\mathrm{R}}(\mathrm{Z}) \delta \mathrm{P}_{\mathrm{R}}(\mathrm{Z}) / \delta \mathrm{Y}_{\mathrm{j}}}{\mathrm{P}_{\mathrm{R}}(\mathrm{Z})} ; \mathrm{j}=\mathrm{p}$ in column 1 and $\mathrm{k}$ in column (2).
$-.001$

$-.012$

(.009)

.066

(.008)

.006

(.015)

$-.009$

(.017)

.025

(.034)

.013

(.038)

$-.010$

$-.024$

(.021)

${ }^{c}$ Column (2) - column (4).

d See Section 4 for a description of the estimation procedure and the bootstrap method used to compute the standard errors. The sample used to estimate equation (4.13) contains 666 observations. The sample used to estimate (4.14) contains 3402 observations. Equations also include assets of the parent in 1984 and assets of the child in 1984, 3 dummy variables for missing asset information for the parent, child, and either the parent or child, and the controls listed in Table 4, note 1 . Current incomes of the parent and child are excluded .

e See Section 5 for the description of time averaged and autoregressive permanent income measures. 
Table A-1: Alternative Estimates of the Effects of Parents' and Child's Current Income on Transfers

A: Efrects of the Parents' and Child's Current Income on Transfers By Number of Siblings ${ }^{1}$

Number of Siblings: $\quad$ E $\delta R / \delta Y p t \quad$ E $\delta R / \delta Y k t \quad \Delta E \delta R / \delta Y . t$

$\begin{array}{llll}\text { Sample Mean } & .028 & -.087 & .115 \\ 0 & .017 & -.144 & .161 \\ 3 & .031 & -.082 & .113\end{array}$

B: Interactions Between Income Variables and the Transfer Probability

Evaluation Point: $\quad$ E $\delta R / \delta Y p t \quad$ E $\delta R / \delta Y k t \quad \Delta E \delta R / \delta Y . t$

$\begin{array}{llll}\text { Sample Means of Controls } & .031 & -.074 & .05\end{array}$

and Income Variables;

Transfer Probability=

Sample Mean

Sample Means of Controls

.020

$-.078$

.098

and Income Variables;

Transfer Probability=

$20 \%$ value

Sample Means of Controls $\quad .042$

and Income Variables;

Transfer Probability=

$(80 \%$ value

C: Estimates Using Instruments for the Parent's and Child's Current Income ${ }^{3}$

Evaluation Point

$\mathrm{E} \delta \mathrm{R} / \delta \mathrm{Y}_{\mathrm{pt}}$

$\mathrm{E} \delta \mathrm{R} / \delta \mathrm{Y}_{\mathrm{kt}}$

$\Delta \mathrm{E} \delta \mathrm{R} / \delta \mathrm{Y}_{\mathrm{jt}}$

Sample Means

$-.004$

$-.145$

141

D: Estimates Using Net Assets in 1989 as the Wealth Measure ${ }^{4}$

Evaluation Point: $\quad E \delta R / \delta Y_{p t} \quad E \delta R / \delta Y_{k t} \quad \Delta E \delta R / \delta Y_{j t}$

$\begin{array}{llll}\text { Sample Means } & -.033 & -.100 & .067\end{array}$

E. Estimates Using Instruments for Parent's and Child's Current Income and 1989 Wealth. 5

Evaluation Point:

Sample Means

$\mathrm{E} \delta \mathrm{R} / \delta \mathrm{Y}_{\mathrm{pt}}$
-.008

$\mathrm{E} \delta \mathrm{R} / \delta \mathrm{Y}_{\mathrm{kt}}$

$-.067$

$\Delta E \delta R / \delta Y_{j t}$

.075 


\section{Footnotes to Table A-1:}

1. We added interactions between 1 (number of siblings +1 ) and the linear current income terms, the permanent income terms, and assets of the parent and child to the probit model (4.14) and the regression model (4.13). The number of siblings is the number of siblings the child reports, regardless of whether they have become splitoffs by 1988 . All other variables are evaluated at the sample mean. Samples sizes used to estimate probit model (4.14) and regression model (4.13) are 2,914 and 560 respectively. The permanent income measures are $\hat{Y}_{p}$ and $\hat{Y}_{k}$ through out the table.

2. We augment the regression model (4.13) with interactions between the income and asset variables and the probit index from the tranfer probability model evaluated at the means of all income and asset variables and the values for each observation of all other variables. In the top row we set all of the demographic control variables and the income and asset variables to the sample means and set the probit index from the transfer probability model to the sample mean. The implied transfer probability is 0.190 . In the middle row and bottom rows we set the transfer probability index to its 20th and 80th percentile values, respectively. The implied transfer probabilities are 0.154 and 0.283 .

3. We replaced the level, square, cube and the interaction terms involving the parents' and kid's current nonasset income with predicted values from a regression against the income of the parent and kid in the previous year, the average of the siblings' reports of their parents' income in 1987, the square and cube for this average, and all other variables in the transfer equation (including all terms involving permanent income and asset terms).

4. We constructed the asset minus debt measure from the detailed information on assets and debts contained in the 1989 household information. We obtained similar results using measure of net worth in 1989 provided on the public use tape. We set the measure of assets minus debt in 1989 to 0 if data are missing or if the head of household in 1989 is not the same as 1988. We included 3 dummies for whether asset data are missing for the parent, the child, or either the parent or the child in the probit model (4.14) and the regression model (4.13). 2.9 percent of the kids and 2.6 percent of the parents were nonresponse in 1989.

5. See footnote 2 for the instruments used for current income. We used the same instruments for 1989 wealth. A dummy is assigned to parents and kids with missing data on 1989 wealth. The sample size for (4.14) is 3,402 , and the sample size for (4.13) is 666 . We evaluate the derivatives at the means of the predicted income and and wealth measures among the sample of children receiving transfers. 
Table A-2: Experiments with Alternative Functional Forms and Sample Exclusions

\begin{tabular}{|c|c|c|c|c|c|}
\hline Panel & $\begin{array}{l}\text { Functional Form and } \\
\text { Sample Exclusions }\end{array}$ & $\begin{array}{l}\text { Estimation Method } \\
\text { for Transfer } \\
\text { Equation }(4.13)\end{array}$ & $E \delta R / \delta Y_{p t}$ & $E \delta R / \delta Y_{k t}$ & $E \delta R / \delta Y_{n}$ \\
\hline A & $\begin{array}{l}\text { Exclude } 35 \text { cases of } \\
\text { transfers }>\$ 5,000 ; \\
\text { transfers and income } \\
\text { in levels. }\end{array}$ & OLS & 013 & .020 & .033 \\
\hline B & $\begin{array}{l}\text { transfers in logs, } \\
\text { income in levels }\end{array}$ & OLS & .012 & -.034 & .046 \\
\hline C & $\begin{array}{l}\text { transfers and income } \\
\text { in logs, income } \\
\text { greater than } \$ 1,000^{3}\end{array}$ & OLS & .006 & -.035 & .041 \\
\hline D & $\begin{array}{l}\text { transfers and income } \\
\text { in levels }{ }^{4}\end{array}$ & LAD & .002 & -.008 & .010 \\
\hline
\end{tabular}

1. The sample sizes for the probit model (4.14) and the regression model (4.13) are 3,367 and 631. The permanent income measures are $\hat{Y}_{p}$ and $\hat{Y}_{k}$ throughout the table.

2. We estimated the conditional expectation function $\bar{R}(Z)$ by first estimating a regression model for the log of transfers, and then using the parameter estimates and estimated error variance of that model to compute $\bar{R}(Z)$ under the assumption that the error term in the log transfer equation is additive and has a log normal distribution. The sample sizes underlying (4.13) and (4.14) are 3,335 and 647.

3. Observations with $Y_{k t}$ and /or $\mathrm{Y}_{\mathrm{t}}$ below $\$ 1,000$ were excluded. Polynomials in the logs of current income and permanent income were used in (4.13) and (4.14). See note 2 for how the regression model for the log of transfers was used to estiimate the conditional expectation function $R(Z)$. The sample sizes underlying (4.13) and (4.14) are 3,309 and 636 .

4. Least absolute deviation regression (LAD) used to estimated (4.13). The sample sizes underlying (4.13) and (4.14) are 3,402 and 666 . 